\title{
1 Viral protein engagement of GBF1 induces host cell 2 vulnerability through synthetic lethality
}

3 Running title: Synthetic lethal targeting of a viral-induced hypomorph

4 Arti T Navare ${ }^{1}$, Fred D Mast ${ }^{1}$, Jean Paul Olivier ${ }^{1}$, Thierry Bertomeu ${ }^{2}$, Maxwell Neal ${ }^{1}$, Lindsay N 5 Carpp $^{3}$, Alexis Kaushansky ${ }^{1,4}$, Jasmin Coulombe-Huntington ${ }^{2}$, Mike Tyers ${ }^{2}$ and John D 6 Aitchison ${ }^{1,4,5}$

1. Center for Global Infectious Disease Research, Seattle Children's Research Institute, Seattle, Washington, USA

2. Institute for Research in Immunology and Cancer, Université de Montréal, Montreal, Quebec, Canada

3. Center for Infectious Disease Research, Seattle, Washington, USA

4. Department of Pediatrics, University of Washington, Seattle, Washington, USA

5. Department of Biochemistry, University of Washington, Seattle, Washington, USA

\section{Correspondence to:}

John D Aitchison, PhD

Professor and Co-Director

Center for Global Infectious Disease Research

Seattle Children's Research Institute

307 Westlake Avenue North, Suite 500

Seattle Washington, 98109-5219

206-884-3125 OFFICE

john.aitchison@seattlechildrens.org

Character count without spaces: 19,391 (no more than 20,000 characters - not including spaces, methods, or references)

24 Keywords: synthetic lethality, viral-induced hypomorph, GBF1, genetic interactions, poliovirus 


\section{Abstract}

28 Viruses co-opt host proteins to carry out their lifecycle. Repurposed host proteins may thus

29 become functionally compromised; a situation analogous to a loss-of-function mutation. We term

30 such host proteins viral-induced hypomorphs. Cells bearing cancer driver loss-of-function

31 mutations have successfully been targeted with drugs perturbing proteins encoded by the

32 synthetic lethal partners of cancer-specific mutations. Synthetic lethal interactions of viral-induced

33 hypomorphs have the potential to be similarly targeted for the development of host-based antiviral

34 therapeutics. Here, we use GBF1, which supports the infection of many RNA viruses, as a proof-

35 of-concept. GBF1 becomes a hypomorph upon interaction with the poliovirus protein $3 \mathrm{~A}$.

36 Screening for synthetic lethal partners of GBF1 revealed ARF1 as the top hit, disruption of which,

37 selectively killed cells that synthesize poliovirus 3A. Thus, viral protein interactions can induce

38 hypomorphs that render host cells vulnerable to perturbations that leave uninfected cells intact.

39 Exploiting viral-induced vulnerabilities could lead to broad-spectrum antivirals for many viruses,

40 including SARS-CoV-2.

\section{Introduction}

42 RNA viruses are prevalent and pervasive pathogens responsible for many global health crises,

43 including the COVID-19 pandemic (Carrasco-Hernandez et al., 2017; Enard and Petrov, 2020;

44 Rosenberg, 2015; Woolhouse and Gaunt, 2007). RNA viruses typically have high mutation rates

45 enabling them to rapidly adapt to new cell types, infect new host species, evade host immune

46 responses, and quickly develop antiviral drug resistance (Sanjuán et al., 2010). Currently, the

47 repertoire of U.S. Food and Drug Administration approved antivirals is limited, targeting only eight

48 out of the known 214 human-infecting RNA viruses (Heaton, 2019). Almost exclusively, these

49 U.S. Food and Drug Administration approved drugs are all designed to target viral proteins

50 (Heaton, 2019; Woolhouse and Brierley, 2018). The dearth of antivirals is likely impacted by the

51 many challenges faced in antiviral drug development, including the small list of target viral proteins 
52 due to their compact genomes, the quick emergence of escape mutants due to the high mutation

53 rates prevalent in many RNA viruses, and the limited therapeutic range of antivirals due to the

54 diversity of RNA virus serotypes which, akin to antimicrobial resistance, has led to limited strain-

55 specific use, or even discontinuation of use, for many antivirals (Heaton, 2019; Irwin et al., 2016;

56 Pennings, 2013; van der Vries et al., 2013). Yet, the same compact-sized genome that gives

57 these viruses an edge over antivirals also makes them obligatory pathogens that rely on host

58 proteins for survival. Thus, although viral genomes drift, they often maintain reliance on the same

59 subset of host factors (Gordon et al., 2020a; Heaton, 2019). The idea of exploiting this over-

60 reliance on their host to develop host-directed antivirals to interfere with host cell factors that are

61 required by the virus, or to more broadly influence immune responses is gaining traction (Gordon

62 et al., 2020b; Kaufmann et al., 2018; Mast et al., 2020; Prussia et al., 2011).

Host-based therapies expand opportunities for treating viral infections (Brass et al., 2008;

Krishnan and Garcia-Blanco, 2014; Zhou et al., 2008). To proliferate, viruses must co-opt common host pathways and cellular machineries by forming protein-protein interactions with host proteins (Basler et al., 2019; Carpp et al., 2014; Gordon et al., 2020b; Lum and Cristea, 2016; Saeed et al., 2020; Stukalov et al., 2020). Due to the essential requirement of these interactions, they are likely to be conserved within viral lineages and can be targeted for developing broadspectrum therapeutics (de Chassey et al., 2014; Meyniel-Schicklin et al., 2012; Pfefferle et al., 2011). Recently, an analysis of published virus-host interaction datasets revealed RNA viruses

71 frequently engage so-called "multifunctional host proteins", a set of 282 highly connected proteins

72 as assessed by their protein-protein interaction networks (Heaton, 2019; Navratil et al., 2009).

73 Targeting these multifunctional host proteins with drugs, many approved by the U.S. Food and

74 Drug Administration could disrupt several crucial steps of viral replication. Inhibiting a virus by

75 targeting the host reduces the possibility of drug resistance and is potentially broad-spectrum if

76 more than one virus relies on the same host protein. However, inhibiting these multifunctional 
77 proteins by drugs may also elicit adverse effects on the host because often these proteins tend

78 to be essential and serve as hubs of complex protein interaction networks (Heaton, 2019; Zotenko

79 et al., 2008). Thus, host-based therapeutic targets should be chosen carefully to avoid potential

80 serious adverse side effects and, ideally, strategies that selectively affect only infected cells

81 should be sought.

The principle of synthetic lethality offers an opportunity for selectively targeting virus

83 infected cells by drugging synthetic lethal $(\mathrm{SL})$ interactors of virus-targeted multifunctional protein

84 hubs (Mast et al., 2020). Synthetic lethality occurs between two genes when a loss-of-function

85 mutation in either gene has little impact on cell viability, but becomes detrimental when paired

86 together resulting in cell death (Dobzhansky, 1946; Hartwell et al., 1997) (Fig. 1A). Such lethal

87 genetic combinations, known as "synthetic lethal pairs" (Nijman, 2011a), are one of many forms

88 of genetic interactions that can occur within cells (Boone et al., 2007; Dixon et al., 2009; Drees et

89 al., 2005; Horlbeck et al., 2018). The existence of synthetic lethality reveals important aspects of

90 the genetic architecture of cells, demonstrating the presence of genetic buffering in organisms

91 due to functional redundancy (Horlbeck et al., 2018; McManus et al., 2009). This SL concept has

92 been successfully applied to cancer therapy and host-targeted drug development (Farmer et al.,

93 2005; Kaelin, 2005; Mendes-Pereira et al., 2009; Turner et al., 2008; Wiltshire et al., 2010) (Fig.

94 1B). For example, loss-of-function mutations in the DNA repair genes encoded by breast cancer

95 type 1 and 2, BRCA1 and BRCA2, cause breast and ovarian cancer but exhibit enhanced

96 sensitivity to inhibitors of poly ADP-ribose polymerase (PARP), another DNA repair enzyme

97 (Farmer et al., 2005). PARP inhibitors selectively killed cancerous cells carrying the loss-of-

98 function BRCA mutation while sparing noncancerous cells (Bryant et al., 2005) and in a clinical

99 trial, PARP anticancer drugs showed a significantly longer progression-free period in patients with

100 breast cancer (Litton et al., 2018). Synthetic lethality-inspired anticancer therapy provides

101 avenues for improved drug specificity and efficacy at lower doses, thereby limiting side effects 
102 (Beijersbergen et al., 2017). Here, we extend the application of this synthetic lethality principle to 103 host-derived antiviral targets.

Virus infection is a perturbation of the host protein-protein interaction (PPI) network. Interactions between virus and host proteins usurp normal protein functions and rewire host PPI networks. Host proteins are considered proviral if loss of function renders the host cell resistant

107 to infection, and antiviral if loss of function improves cell permissibility to infection. Infected cells 108 exhibit altered metabolic requirements (Thaker et al., 2019), signaling pathways (Gaur et al., 109 2011), intracellular transport pathways (Belov et al., 2007) and other morphological and molecular 110 characteristics relative to the noninfected cells. In such situations, infected cells may depend on 111 a different complement of proteins than their uninfected counterparts (Mast et al., 2020). This 112 state-specific vulnerability may be a target for host-based therapeutics based on the well113 established principle of synthetic lethality. For example, if two host cell proteins have a SL 114 relationship and the function of one protein is hijacked by a viral protein, then cells may become 115 dependent on the function of the second protein. In contrast, cells that are not altered by the virus, 116 i.e., those that are uninfected, will be unimpacted by blocking the second protein, since the 117 elimination of a single half of the SL pair does not result in a phenotype. Rational targeting of SL 118 protein pairs in which the function of one partner is reduced specifically in the infected cell; a 119 situation equivalent to the mutant gene in cancer, is a novel framework for taking advantage of 120 the intrinsic differences of infected cells to achieve selective targeting (Fig. 1C). We hypothesize 121 that viral-host PPIs generate protein-based, viral-induced (vi)-hypomorphs of host factors in 122 infected cells, thereby specifically sensitizing infected cells to targeting SL/synthetic sick partners 123 of these vi-hypomorphs. To test this hypothesis, we selected the Golgi-specific brefeldin A124 resistance guanine nucleotide exchange factor (GBF1) (Claude et al., 1999) because it is a critical 125 proviral host factor for the replication of several families of RNA viruses, including Picornaviridae, 126 Coronaviridae, Flaviviridae, Herpesviridae, Filoviridae, and Rioviridae (Belov et al., 2008b; Carpp 
127 et al., 2014; Farhat et al., 2018; Goueslain et al., 2010; Lanke et al., 2009; Martínez et al., 2019;

128 Verheije et al., 2008; Yamayoshi et al., 2010). Considering so many viruses rely on GBF1, it 129 seems unlikely that these viruses would readily overcome GBF1 dependence. GBF1 mediates 130 recruitment of coat proteins (Manolea et al., 2008), lipid modifying enzymes (Ellong et al., 2011), 131 and protein tethers (García-Mata and Sztul, 2003) to Golgi membranes. It thus plays a central 132 role in vesicular transport through the Golgi, the structural integrity of Golgi membranes, and the 133 maintenance of lipid homeostasis (Beller et al., 2008; Donaldson and Jackson, 2011; Guo et al., 134 2008; Sáenz et al., 2009; Soni et al., 2009). With its dynamic membrane-modulating functions 135 GBF1 has also been implicated in coatomer-dependent protein delivery to lipid droplets 136 (Kaczmarek et al., 2017; Soni et al., 2009).

Many RNA viruses encode proteins that bind GBF1 directly, including the nonstructural 138 proteins 3A of poliovirus (Belov et al., 2008a; Teterina et al., 2011) and coxsackievirus (Wessels 139 et al., 2006a; c), and nonstructural protein 5 of dengue (Carpp et al., 2014). Recently, two SARS140 CoV-2 proteins, membrane (M) and orf6, were identified to be directly binding or in close proximity 141 of GBF1, respectively (Laurent et al., 2020; Stukalov et al., 2020). In the case of poliovirus 142 infection, 3A redistributes GBF1 to viral replication complexes during early stages of replication 143 and subverts its guanine nucleotide exchange factor (GEF) function in the infected cells (Carpp 144 et al., 2014; Richards et al., 2014; Wessels et al., 2007, 2006b; c), suggesting that poliovirus 145 protein 3A may attenuate GBF1's normal function creating a hypomorph, rendering cells 146 susceptible to disruption of proteins synthetically lethal with GBF1. Here, we provide proof-of147 concept that SL partners of vi-hypomorphs can be targeted to selectively eliminate infected cells 148 while leaving uninfected cells intact. We do this by performing a genome-wide chemogenomic 149 CRISPR screen to identify SL partners of GBF1, validating the top candidates, and demonstrating 150 that shRNA-mediated silencing of the GBF1 SL interacting partner, ARF1, selectively kills cells 151 expressing poliovirus protein 3A. 


\section{Results and Discussion:}

153 In order to identify putative synthetic lethal partners of GBF1, we screened a high-complexity 154 extended-knockout CRISPR library of 278K single guide RNAs (sgRNAs) that target 19,084

155 RefSeq genes, 20,852 alternatively-spliced genes, and 3,872 predicted genes, among additional 156 controls, in NALM-6 human B cell precursor leukemia cells (Bertomeu et al., 2018) (Fig. 2A).

157 These cells harbor a genomic doxycycline-inducible Cas9 that enables regulatable, uniform, and 158 robust gene silencing across the pooled library (Wang et al., 2014). Relative changes in sgRNA 159 frequencies were obtained from sequencing populations of the CRISPR libraries cultured in the 160 presence or absence of Golgicide A (GCA), a potent and specific inhibitor of the GEF activity of 161 GBF1 (Sáenz et al., 2009) (Fig. 2A). The concentration of $4 \mu M$ GCA used in the screen was 162 determined prior to the screen to maximize both enrichment, i.e., positive selection for rescue of 163 compound toxicity, and depletion, i.e., negative selection for SL interactions (Fig. S1). sgRNA 164 frequencies were determined by sequencing, and relative fold changes in sgRNA abundances between GCA- and mock-treated samples were reported (Table S1 and Fig. 2B).

167 overrepresented genes in the GCA treated samples relative to the controls (Fig. 2B; white circles).

168 Underrepresented genes represent putative SL partners of GBF1 and the top SL candidate, ADP-

169 ribosylation factor 1 (ARF1), is a small GTPase that regulates the recruitment and assembly of

170 COP I on Golgi and ERGIC membranes (Liang and Kornfeld, 1997). GBF1 facilitates GDP to GTP

171 exchange on ARF1 to regulate recruitment of effectors such as coat protein and lipid-modifying

172 enzymes to ARF1-localized membrane sites and creates a domain competent for secretory cargo

173 transport (Claude et al., 1999; Donaldson and Jackson, 2011; Kawamoto et al., 2002). In yeast,

174 a negative genetic interaction exists between ARF1 and the yeast GBF1-ortholog, guanine

175 nucleotide exchange on ARF 1 (GEA1) (Surma et al., 2013), and GEA1 overexpression rescues

176 an arf1 1 temperature sensitive growth defect (Chantalat et al., 2003). Functional enrichment 
177 analysis of the 53 putative SLs of GBF1 showed enrichment for genes in the early secretory 178 pathway, and genes involved in the misfolded protein-triggered ER stress response (Fig. 2C, D). 179 GBF1 depletion is known to induce an unfolded protein response in the ER (Citterio et al., 2008).

180 Thus, putative SLs of GBF1 are likely functionally redundant with GBF1, an attribute of the genetic 181 interactions between SLs that offers buffering in the event of a loss of function of one of the SL 182 genes (Hartman IV et al., 2001; Mast et al., 2020). As evident by a PPI network, the 53 GBF1-

183 SLs and the 17 GBF1 suppressors are functionally related and can be grouped into a few distinct 184 functional clusters (Fig. 2D). For example, one cluster of GBF1-SLs are enriched in ER stress, 185 unfolded protein response, and ER-associated protein degradation pathways, while eight out of 186 the seventeen GBF1 suppressors contribute to ER-Golgi vesicular transport (Fig. 2D). GBF1-SLs 187 also include a cluster of RNA binding proteins, and members of the KICSTOR (Wolfson et al., 188 2017) and DEPTOR (Peterson et al., 2009) complexes that negatively regulate mTOR signaling 189 (Fig. 2D). Several genes from both lists possess GTPase activity, e.g., the GBF1-SLs: ARF1, 190 TMED10, DRG2, RAB5C, YIP5, RAB3GAP2, and the GBF1 suppressors: ARF1GAP1, SAR1A1, 191 ARF4, and ARF5 (Fig. 2D). ARF4, a class II ARF implicated in endosomal morphology and 192 retrograde transport to the Golgi (Nakai et al., 2013), was the top overrepresented gene (Fig. 2B). 193 A previous large-scale insertion mutagenesis screen identified a role for ARF4 in conferring 194 resistance to Golgi disrupting agents (Reiling et al., 2013), suggesting a protective role of ARF4 195 against GCA toxicity. Just over half of the GBF1-SLs and suppressors identified in our screen are 196 directly targeted by viral proteins (Fig. 2D, circles with red boundaries). We searched this list against the Drug Gene Interaction Database (Cotto et al., 2018) for 198 potential 'druggability' (http://dgidb.org/search categories) and selected four druggable, putative 199 synthetic lethal interactors of GBF1 (Fig. 2A). In addition to ARF1, we selected: heat-shock protein 20090 (HSP90), a protein chaperone with ATPase activity (Rowlands et al., 2010); C-terminal Src 201 kinase (CSK), which negatively regulates Src family kinases and has roles in cell growth, 
202 differentiation, migration and immune response (Okada, 2012); and protein kinase, AMP203 activated, alpha 1 (PRKAA1), the catalytic subunit of the 5'-prime-AMP-activated protein kinase 204 (AMPK) with roles in regulating cell stress and metabolism (Sanli et al., 2014). These four putative 205 SL partners of GBF1 were silenced in HeLa cells along with methylsterol monooxygenase 1 206 (MSMO1), included as a control because it did not show depletion or enrichment in sgRNA 207 abundance, and ARF4, because it was the topmost significantly overrepresented in our drug 208 CRISPR screen (Table S1 and Fig. 2A). The knockdown (KD) cell lines were incubated with 1.5 $209 \mu \mathrm{M}$ or $4 \mu \mathrm{M}$ of GCA/DMSO-alone for $48 \mathrm{~h}$ before measuring viabilities. Synthetic lethal effects of 210 combining GCA with shRNA-mediated depletion were observed in ARF1 KD cells with only $40 \%$ 211 or $50 \%$ viability as compared to the DMSO-treated cells at $4 \mu \mathrm{M}$ and $1.5 \mu \mathrm{M}$ GCA concentration, 212 respectively (Fig. 3A). When the viability of each KD cell line was compared to that of the MSMO1 $213 \mathrm{KD}$ control, the decrease in the viability was statistically significant for $A R F 1 \mathrm{KD}$ at both 214 concentrations, confirming the results of the chemogenomic screen. A GCA dose-response assay 215 monitoring cell growth inhibition as a function of GCA concentration showed a nearly two-fold 216 reduction in $\mathrm{IC}_{50}$ value for $A R F 1 \mathrm{KD}$ cells as compared to the control (Fig. $\left.3 \mathrm{~B}\right)$, further validating 217 the SL interaction between GBF1 and ARF1. consequently generating vi-hypomorphs in infected cells. As a result, the infected cells may 220 become more vulnerable to drugs that target SL partners of the vi-hypomorph than in uninfected 221 cells lacking the vi-hypomorph. We tested this hypothesis in the context of expressing poliovirus 222 3A because it recruits GBF1 to sites of poliovirus replication (Belov et al., 2007, 2008a; Richards 223 et al., 2014). The dynamics of GBF1-3A interactions observed during viral infection, including 224 GBF1-mediated ARF1 activation and translocation, are retained in cells ectopically expressing 225 the viral protein alone (Belov et al., 2005, 2007; Richards et al., 2014; Wessels et al., 2006a), 226 which allows for testing the formation of a GBF1 vi-hypomorph in a simpler yet relevant model 
227 system without the confounding effects of viral infection. We tagged poliovirus protein $3 \mathrm{~A}$ with a 228 modified FLAG epitope (FLAG*) (Teterina et al., 2011) and transiently expressed it in HeLa cells 229 (Fig. 4). Poliovirus isolates expressing a modified FLAG tagged 3A are stable and yielded 3A230 tagged viruses with similar fitness to the wild-type untagged virus, suggesting that this protein 231 behaves in a similar manner as the wildtype protein (Teterina et al., 2011). The FLAG* tag is 232 similar to the conventional 8-amino acid (DYKDDDDK) FLAG tag, but with the last aspartic acid 233 replaced by tyrosine and is recognized by a-FLAG antibodies (Teterina et al., 2011) (Fig. 4A). N234 terminal, FLAG*-tagged 3A, or an empty plasmid control was transiently transfected into HeLa 235 cells for 24 h. $3 A-F L A G *$ and associated proteins were affinity purified on magnetic beads 236 conjugated with a-FLAG antibodies (Fig. 4A). Isolated complexes were washed, and the eluate, 237 along with a fraction of the load and wash were resolved by SDS-PAGE, transferred to 238 nitrocellulose, and probed with $\alpha-F L A G$ and $\alpha-G B F 1$ antibodies (Fig. 4A). A band of $\sim 10 \mathrm{kDa}$ was 239 detected in the eluate corresponding to the $F L A G^{*}-3 A$ protein and a slower migrating, high 240 molecular weight band of $\sim 200 \mathrm{kDa}$, corresponding to GBF1, was detected in the eluate of GBF1 241 immunoprecipitated from cell expressing $3 A-F L A G^{*}$, but not from cells transfected with the empty 242 plasmid control (Fig. 4A). This observation confirmed that the ectopically expressed 3A-FLAG* 243 protein retained its ability to physically interact with GBF1, as reported previously (Teterina et al., 244 2011).

We next tested if the physical interaction between 3A and GBF1 had consequences for

246 GBF1 function, suggestive of a GBF1 hypomorph. HeLa cells were transduced with lentivirus 247 delivering an empty control or 3A-FLAG*and cells were fixed and immunostained with a-FLAG248647 (red) and a-GBF1-488 (green), antibodies (Fig. 4B). GBF1 was visualized as puncta enriched 249 in a juxtanuclear position consistent with a Golgi localization in the control cells (Fig. 4B; red 250 arrows). This juxtanuclear enrichment was lost in 3A transduced cells and the GBF1 puncta were 251 instead found redistributed throughout the cytoplasm (Fig. 4B). We quantified this redistribution 
252 by measuring the distance of all GBF1 puncta from the nearest nucleus for each cell in the dataset

253 (Fig. 4C, D). This quantification revealed an increase in GBF1 puncta localized away from the

254 nucleus in $3 \mathrm{~A}$ transduced cells that was statistically significant compared to control. The depletion

255 of Golgi-localized GBF1 upon expression and interaction with poliovirus 3A is consistent with 3A

256 inducing a GBF1-hypomorph.

Having identified $A R F 1$ as a SL interactor of GBF1 and established that a GBF1

hypomorph may be induced by expression of poliovirus $3 \mathrm{~A}$, we next asked if the $3 \mathrm{~A}$-induced

hypomorphic state of GBF1 was sufficient to drive a synthetic lethal interaction in cells depleted

260 of ARF1. HeLa cells were treated with shRNA to ARF1, or, as a control, shRNA to MSMO1, which

261 had no effect in the GBF1 SL screen (Fig. 2B), and the depletion of ARF1 was evaluated by

262 western blotting (Fig. S2). 3A-FLAG*or an empty plasmid control was transiently transfected into

263 both KD cell lines and expression of $3 A-F_{A A G}{ }^{*}$ was detected by flow cytometry (Fig. 5A). The

264 viability of the ARF1 KD cells was significantly decreased by the expression of $3 A-F L A G *$ (Fig.

265 5B). By comparison, the MSMO1 KD cells were not significantly affected (Fig. 5B). Importantly,

266 this decrease in cell viability, $30 \% \pm 3.5$, (Fig. 5B) was comparable to the percent of $A R F 1 \mathrm{KD}$

267 cells expressing $3 A-F L A G *, 37 \% \pm 3.0$ (Fig. 5A), supporting our hypothesis that the $3 A$ expressing

268 cells in which a hypomorph of GBF1 was generated due to GBF1-3A interaction were selectively

269 killed only in the absence of a functional ARF1 (Fig. 5).

270 Synthetic lethality is conventionally described as a type of genetic interaction between two

271 nonessential genes that participate in a parallel or redundant process to carry out an essential

272 function, where mutations in either gene alone does not affect cell viability, but mutations in both

273 genes results in cell death (Nijman, 2011b). In this manuscript, we have extended the idea of

274 synthetic lethality to interactions involving a virus-induced hypomorph. In poliovirus, the viral

275 replication complex protein 3A physically interacts with GBF1 (Belov et al., 2008a; Teterina et al., 
276 2011) and re-localizes it to poliovirus replication complexes (Richards et al., 2014). We show

277 here, that this re-localization sensitizes and reduces the viability of cells depleted of ARF1.

278 In summary, viral-host protein-protein interactions that result in the functional attenuation

279 of the host factor offer a promising avenue for therapeutics based on the principle of synthetic

280 lethality (Mast et al. 2020). In this context, the infected cell becomes selectively dependent upon

281 the otherwise nonessential SL partner of the vi-induced hypomorph. Considering that GBF1 is a

282 common target of many viruses, it is tempting to speculate that SL interactors of GBF1, or other

283 common proviral factors, might be candidates for broad-spectrum host-based antivirals. Our

284 proof-of-concept experiments provide a rational approach for identifying these novel antivirals.

285 Our strategy to target SL interactions of the vi-induced hypomorph has a potential to change the

286 current paradigm for host-based therapeutics that can lead to broad spectrum antivirals and can

287 be applied to other intracellular pathogens. 


\section{Materials and Methods}

\section{Cell culture and plasmids}

290 HeLa cells (ATCC CCL-2) and HEK293-FT (ThermoFisher) were cultured at $37{ }^{\circ} \mathrm{C}$ in $5 \% \mathrm{CO}_{2}$ in 291 medium composed of high glucose Dulbecco's modified eagles medium (DMEM, Gibco)

292 supplemented with 10\% (v/v) heat inactivated fetal bovine serum (VWR), 1x 293 penicillin/streptomycin (ThermoFisher Scientific), 20 mM L-glutamine (Gibco), 1× nonessential 294 amino acids (Gibco), 1× sodium pyruvate (Gibco) and $10 \mathrm{mM}$ HEPES buffer (Gibco) (complete 295 media).

296 Cell line authentication was provided by the American Type Culture Collection and 297 ThermoFisher Scientific. In general, cells were passaged 5-10 times and periodically tested for 298 contamination using MycoAlert ${ }^{\mathrm{TM}}$ Mycoplasma Detection (Lonza) kit.

299 A doxycycline-inducible Cas9 clonal cell line of NALM-6 cells (Wang et al., 2009) was 300 cultured at $37^{\circ} \mathrm{C}$ in $5 \%$ CO2 in RPMI-1640 medium supplemented with $10 \%(\mathrm{v} / \mathrm{v})$ heat inactivated 301 fetal bovine serum, as described (Bertomeu et al., 2017).

302 Agarose stabs of $E$. coli (DH10B) harboring custom-made mammalian expression vector pD2109303 EF1 was purchased from ATUM (Newark, CA USA). pD2109-EF1 encodes poliovirus protein 3A 304 with a modified FLAG tag (DYKDDDYKK) inserted at the N-terminus. The modified FLAG tag 305 (referred here as $\mathrm{FLAG}^{*}$ ), contains a tyrosine $(\mathrm{Y})$ residue at position 7 instead of aspartic acid 306 residue (D) found in a typical FLAG tag sequence. A complete sequence of the 3A-FLAG*protein 307 with the inserted FLAG* tag (in bold) is as follows:

308 GPLQYKDYKDDDYKDLKIDIKTSPPPECINDLLQAVDSQEVRDYCEKKGWIVNITSQVQTERNIN 309 RAMTILQAVTTFAAVAGVVYVMYKLFAGHQ 
312 cells by plasmid DNA transfection. We used an empty plasmid pLKO1.puro with comparable size

313 to pD2109-EF1 as a control for transfections.

Bacterial glycerol stocks of MISSION® shRNAs were purchased from Sigma Aldrich for:

315 ARF1 (clone ID: TRCN0000039874, TRCN0000039875), ARF4 (TRCN0000298174,

316 TRCN0000047940), MSMO1 (TRCN0000230198, TRCN0000046245), CSK(TRCN0000199500,

317 TRCN0000000804), HSP90 (TRCN0000008747,TRCN0000315415), and PRKAA1

318 (TRCN0000000861, TRCN0000000859). shRNA plasmid DNA was purified using NucleoBond

319 Xtra Midiprep kit by following manufacture's protocol.

\section{Chemogenomic screening and data analysis}

321 Genome-wide custom extended-knockout (EKO) pooled library was created in a B-cell lymphoma

322 line using a published protocol (Bertomeu et al., 2018). Briefly, a clone of the NALM-6 cells

323 expressing Cas9 under a doxycycline-inducible promoter was transduced with the 278K sgRNAs

324 followed by selection over blasticidin, and induction of knockdown of genes with $2 \mu \mathrm{g} / \mathrm{ml}$

325 doxycycline over a seven-day period. At that time (day 0), the EKO library was split into separate

326 flasks, one containing $4 \mu \mathrm{M} \mathrm{GCA}$, three containing media alone and two containing $0.1 \%$ DMSO

327 and each library flask was grown for eight more days. During this period, cell counts were made

328 every two days and population doublings were monitored. After each cell count, cells were diluted

329 down to 28 million cells per flask and fresh media was added. Whereas all other samples were

330 grown in T-75 flasks from days 0-8 of the screen, one of the untreated control samples was grown

331 in a T-175 flask and was diluted down to 70 million cells every two days instead of 28 million.

332 sgRNA sequences were recovered by PCR of genomic DNA, reamplified with Illumina adapters,

333 and sequenced on an Illumina HiSeq 2000 instrument. The GCA-treated sample DNA was later

334 re-sequenced on an Illumina Next-Seq 500 instrument to increase coverage. Illumina sequencing

335 reads were aligned to the theoretical EKO library using Bowtie 2.2.5, with the -norc (no reverse

336 complement) option and otherwise default parameters. sgRNA read counts were tabulated from 
337 all successfully aligned reads. Having found no significant differences between untreated and

$338 \quad 0.1 \%$ DMSO-treated controls, we opted to add together the sgRNA read counts from all control

339 samples to generate a more robust estimate of the expected sgRNA frequency distribution. We

340 used RANKS (Robust Analytics and Normalization for Knockout Screens) (Bertomeu et al., 2018)

341 with default parameters to generate gene scores $p$-value and FDR values, comparing the sgRNA

342 read counts of the GCA-treated sample to those of the controls (Table S1). We also calculated

343 gene-level $\log _{2}$ fold-changes in sgRNA representation by first summing across each sample the

344 reads of all (usually 10) sgRNAs targeting the gene to calculate a single ratio normalized to the

345 ratio of total aligned read counts per sample (Table S1). This approach effectively downweighs

346 less well represented guides in contrast to the traditional approach of taking the average of the

347 individual sgRNA fold-changes. Reported gene essentiality and essentiality rank in Table S1 are

348 from a previous screen (Bertomeu et al., 2018).

349 Ontology biological process enrichment analysis was performed on the putative GBF1-

350 SLs (FDR < 0.05) using ClusterProfiler (Yu et al., 2012) where the list was analyzed against the

351 entire KO genes from the CRISPR library to functionally classify the SL genes.

352 The list of 70 genes (53 GBF1- SLs and 17 GBF1 suppressors) passing the FDR cut off

$353(<0.05)$ was submitted to the STRING database (Szklarczyk et al., 2019) to map evidence-based

354 PPIs with the active interaction sources: textmining, experiments, databases, co-expression,

355 neighborhood, gene-fusion, and co-occurrence. The resulting PPI network was visualized using

356 Cytoscape (3.8.2) (Shannon et al., 2003) in a radial layout, with proteins denoted as circles and

357 interactions as edges. The 70 genes were also searched against a virus-host PPI database,

358 VirHostNet (v2.0) (Navratil et al., 2009), to identify known interactors of virus proteins.

\section{10x Lentivirus stock preparation}

360 Glycerol stocks of the validated MISSION shRNA vectors for ARF1, PRKAA1, HSP90, CSK,

361 MSMO1 and ARF4, were obtained from Sigma Aldrich (St. Louis, MO). 10× stocks of non- 
362 replicating lentiviral stocks were generated by transfection of HEK293-FT cells as follows: $4 \times 10^{6}$

363 HEK293-FT cells were plated on poly-L-lysine coated $10 \mathrm{~cm}$ dishes to achieve $70-80 \%$ confluency

364 at time of transfection. The following day, transfection mixtures were prepared by mixing $20 \mu \mathrm{l}$

365 Polyethylenimine MAX (Polysciences Inc, Warrington, PA) prepared at $1 \mathrm{mg} / \mathrm{ml}$, together with

$3664.75 \mu \mathrm{g}$ of transgene shRNA constructs, $1.5 \mu \mathrm{g}$ of viral envelope plasmid (pCMV-VSV-G), and

$3673.75 \mu \mathrm{g}$ of viral packaging plasmid (psPax2). After incubating for $10 \mathrm{~min}$ at room temperature in

368 DMEM, transfection complexes were added dropwise to cells. After overnight incubation, cells

369 were washed to remove the transfection mixture and replaced with $10 \mathrm{ml}$ of pre-warmed media.

370 Lentivirus-containing supernatant was harvested $48 \mathrm{~h}$ later, centrifuged for $5 \mathrm{~min}$ at $900 \mathrm{~g}$ to

371 remove cell debris, passed through $0.45 \mu \mathrm{m}$ syringe filters, and collected by centrifugation for $4 \mathrm{~h}$

372 at $78,900 \mathrm{~g}$. Supernatants were decanted and pelleted lentiviruses were re-suspended in $0.1 \mathrm{ml}$

373 Opti-MEM (Gibco) to obtain 10x lentivirus concentrates and stored at $-80{ }^{\circ} \mathrm{C}$ until use. A similar

374 protocol was used to prepare $10 \times$ lentivirus stocks of $3 A-F L A G *$.

\section{5 shRNA-mediated gene knockdowns}

376 To induce knockdown of the top putative GBF1 SL genes, 300,000 HeLa cells were transduced

377 with lentiviral supernatants in 6-well plates. At time of plating, $10 \times$ lentivirus concentrates were

378 diluted in $1 \mathrm{ml}$ of Opti-MEM containing $8 \times 10^{-3} \mu \mathrm{g} / \mathrm{ml}$ of polybrene (Sigma Aldrich; St. Louis, MO)

379 and incubated overnight at $37^{\circ} \mathrm{C}$. The following day, the transfection mix was replaced with $2 \mathrm{ml}$

380 of pre-warmed complete media and incubated for $24 \mathrm{~h}$. In order to select for cells with stable

381 integration of shRNA transgenes, overnight media was replaced with complete media containing

$3821.5 \mu \mathrm{g} / \mathrm{ml}$ puromycin. Cells were selected for at least 3 days prior to experiments. Stably silenced

383 knockdown cell lines (ARF1 KD, HSP90 KD, CSK KD, PRKAA1 KD, MSMO1 KD, and ARF4 KD)

384 were harvested by trypsinization in $0.25 \%$ trypsin-EDTA, washed in pre-warmed PBS, cells were

385 counted, and a small aliquot was cells were saved for western blot analysis to verify protein level

386 knockdown efficiencies for each gene. 


\section{Western blot analysis}

388 Cell pellets of the KD cell lines were re-suspended in a chilled IP lysis buffer (20 mM HEPES$389 \mathrm{KOH}, \mathrm{pH} 7.5,1 \%(\mathrm{w} / \mathrm{v})$ Triton $\mathrm{X}-100,0.5 \%(\mathrm{w} / \mathrm{v})$ sodium deoxycholate, $110 \mathrm{mM}$ potassium 390 acetate, $2 \mathrm{mM} \mathrm{MgCl}$, $25 \mathrm{mM} \mathrm{NaCl}$, and 1× cOmplete protease inhibitor cocktail (Roche)) and 391 lysed by sonicating for 1 min using a probe sonicator (QSonica) operated at an amplitude of 10 392 with $10 \mathrm{~s}$ on-off cycles. Lysates were centrifuged at $\sim 100,000 \mathrm{~g}$ for $5 \mathrm{~min}$ and supernatants were

393 transferred into a fresh tube. Protein concentrations were determined by bicinchoninic acid assay

394 (ThermoFisher Scientific) and working solutions of lysates at concentrations of $15-30 \mu \mathrm{g}$ total 395 proteins per $30 \mu$ were prepared with $1 \times$ lithium dodecyl sulfate (LDS) sample buffer with reducing 396 reagent (NuPAGE, ThermoFisher Scientific) followed by heating at $70{ }^{\circ} \mathrm{C}$ for 20 min on a 397 Thermomixer (Eppendorf). $30 \mu$ l of the reduced lysate was loaded per well on $4-20 \%$ or $12 \%$, for 398 ARF1 KD and ARF4 KD, Bis-Tris gels (NuPAGE, ThermoFisher Scientific) and protein bands 399 were resolved at a constant voltage of $170 \mathrm{~V}$ for $1 \mathrm{~h}$. Protein bands were transferred on PVDF 400 membranes using Xcell2 blot module (ThermoFisher) for $2 \mathrm{~h}$ at a constant voltage of $37 \mathrm{~V}$ and 401 membranes were blocked in 5\% (w/v) milk in TBST for $1 \mathrm{~h}$ at room temperature. After blocking, 402 membranes were incubated with primary antibodies (Abcam and GeneTex) against proteins of 403 interests: ARF1 (ab58578 at 1:1000 dilution), ARF4 (ab190000 at 1:1000 dilution), HSP90 404 (GTX101448 at 1:1000 dilution), CSK (GTX107916 at 1:500 dilution), CSNK2A (13-453 at 1:500 405 dilution), PRKAA1 (ab32047 at 1:1000 dilution) and MSMO1 (ab116650 at 1:500 dilution) and 406 washed thrice in TBST buffer before incubating with appropriate HRP-conjugated secondary 407 antibodies (goat $\alpha$-mouse or $\alpha$-rabbit; 1:2500 dilution). Following incubation, membranes were 408 washed and developed using chemiluminescent substrates (Advansta WesterBright). Images 409 were acquired using a FluorChem imager (Protein Simple), and membranes were stripped using 410 a stripping buffer (ThremoFisher), blocked, incubated with HRP- $\alpha-\beta$-actin $(a b 49900 ; 1: 25,000)$

411 and imaged as before. Images were cropped, adjusted for brightness and contrast, and labelled 412 using Adobe Photoshop and InDesign. 


\section{FLAG*-tagged 3A lentivirus direct plasmid transfection}

414 FLAG*-tagged 3A plasmid DNA were directly transfected in HeLa cells for performing

415 immunofluorescent imaging and co-immunoaffinity purification assays using TransIT transfection

416 reagent (Mirus) by following the manufacturer's recommended protocol. Briefly, transfection mix

417 was prepared in a serum free Opti-MEM media by adding 3A-FLAG* DNA and TransIT reagent

418 in a ratio of $1: 3(\mathrm{wt} / \mathrm{v})$ and the mixture was incubated for $30 \mathrm{~min}$ at room temperature. After

419 incubation, the transfection mix volume equivalent to $1 \mu \mathrm{g}$ and $15 \mu \mathrm{g}$ total DNA was added to

42060,000 HeLa cells for immunofluorescence imaging and $3 \times 10^{6}$ cells for co-immunoaffinity

421 purification assays, respectively.

\section{Flow cytometry}

423 Transduced HeLa cells were trypsinized using $0.05 \%$ (w/v) Trypsin-EDTA and transferred into a

424 U-bottom 96-well plate. Cells were washed twice in PBS supplemented with 10\% (v/v) FBS and 425 incubated with Live/Dead Fixable stain (excitation/emission: 416/451; ThermoFisher Scientific) 426 for 15 min on ice. Excess stain was removed by washing twice and cells were fixed using $4 \%$ 427 (w/v) paraformaldehyde (Sigma) for $30 \mathrm{~min}$. Fixative solvent was removed, and cells were washed 428 thrice in PBS by centrifugation at $700 \mathrm{~g}$ for $5 \mathrm{~min}$. Supernatant wash solution was removed, and 429 cells were incubated in PBS with $0.1 \%(w / v)$ Triton X-100 for 15 min to permeabilize the cells. 430 After cell permeabilization, the cells were blocked for $1 \mathrm{~h}$ in PBS containing 2\% (w/v) BSA 431 (manufacturer) and 1\% (w/v) Triton X-100. Cells were then stained with R-phycoerythrin (PE)432 conjugated $\alpha-F L A G$ (637310; Biolegends, 1:1000 dilution) for $1 \mathrm{~h}$ on ice. After staining, cells were 433 washed thrice in the blocking buffer and analyzed on a LSRII flow cytometer (BD Biosciences).

434 The percentage of cells expressing $3 A-F L A G^{*}$ were determined by analyzing the flow cytometry 435 data using FlowJo software (Tree Star, Inc.). Cell populations were filtered using the forward and 436 side scatter to remove cell debris and cell doublets. The remaining single cell subpopulation was 437 then divided using the intracellular PE straining into a 3A-FLAG* positive and negative populations 
438 and percentages of positive and negative cells of the total single cells were reported. Experiments

439 were performed in duplicate.

\section{Immunofluorescence microscopy}

441 HeLa cells were plated in 12 well plates containing $12 \mathrm{~mm}$ no.1.5 circular glass coverslips

442 (Fisherbrand) at a cell density of 60,000 per well and transfected with FLAG*-3A or an empty

443 plasmid control. Cells were fixed $24 \mathrm{~h}$ post-transfection with $2 \%(\mathrm{w} / \mathrm{v})$ paraformaldehyde (Sigma)

444 for $30 \mathrm{~min}$, permeabilized with $0.1 \%(\mathrm{w} / \mathrm{v})$ Triton $\mathrm{X}-100$, and blocked with $2 \%(\mathrm{w} / \mathrm{v}) \mathrm{BSA}, 0.1 \%$

445 (w/v) Triton X-100 in PBS (blocking buffer). After blocking, cells were incubated with rabbit $\alpha-$

446 GBF1 (abcam; ab86071 1:1000 dilution) and mouse a-FLAG (Sigma F1804; 1:200 dilution) for 1

$447 \mathrm{~h}$ followed by $1 \mathrm{~h}$ staining with secondary antibodies goat $\alpha$-rabbit AlexaFluor-488, and goat $\alpha-$

448 mouse AlexaFluor-594 (Invitrogen), used at a 1/1000 dilution. The coverslips were mounted on

449 Superfrost ${ }^{\mathrm{TM}}$ microscope slides (Fisherbrand), nuclei were stained with DAPI, and the cells were

450 cleared with Prolong Glass (Invitrogen). Images were acquired with a 100× NA 1.4 objective

451 (Olympus) on a DeltaVision Elite High-Resolution Microscope (GE Healthcare Life Sciences).

452 Fluorescence excitation was driven by an Insight SSI solid state light engine (Cytiva) and

453 fluorescence emission was collected by a CoolSnap HQ2 CCD camera (Photometrics). The sides

454 of each CCD pixel are $6.45 \mu \mathrm{m}$. Image $\mathrm{z}$ stacks were acquired with $0.2 \mu \mathrm{m}$ steps and $25-27$

455 images per stack. Images were deconvolved with a classic maximum likelihood estimation

456 algorithm using Huygens software (Scientific Volume Imaging; The Netherlands) and

457 experimentally determined point spread functions captured by imaging PS-Speck ${ }^{\mathrm{TM}}$ beads

458 (Invitrogen) under experimental conditions, as done previously (Mast et al., 2018; Vijayan et al., 459 2019).

\section{Image quantification}

461 Images were processed using Imaris software (Bitplane) to quantify the number of GBF1 puncta 462 per cell. Initial cell segmentation was performed by summing the fluorescent intensities from all 
463 channels and using the 'Surface' command to threshold the images. This segmentation was

464 refined using the 'Cell' command. Cell nuclei were defined using the DAPI channel and cell

465 boundaries defined using a watershed algorithm seed by the 'one nucleus per cell' function in

466 order to split touching cells. Next, the GBF1-488 channel was selected for detecting GBF1 puncta

467 using the 'detect vesicle' function. Statistical values for 'Vesicle intensity sum' and 'vesicle

468 distance to closest nucleus' for each GBF1 puncta per cell were exported for 42 cells from control

469 samples, and from 13 cells of 3A-FLAG* transfected cells. Distances of GBF1 puncta from the

470 nearest nucleus in 3A-FLAG* cells were compared to distances from control cells using Wilcoxon

471 rank-sum tests. Comparisons were made using all observed puncta and, separately, using only

472 puncta more than $20 \mathrm{~mm}$ from the closest nucleus.

\section{Coimmunoprecipitation}

474 HeLa cells were transfected with $1 \mu \mathrm{g}$ DNA of each of the FLAG*-3A and an empty control

475 plasmid. At $24 \mathrm{~h}$ post-transfection, cells were lysed using mild sonication in IP lysis buffer (20 mM

476 HEPES, 1\% (w/v) Triton X-100, 2 mM Magnesium chloride, 25 mM Sodium chloride, 110 mM

477 Potassium acetate, and $0.2 \%(\mathrm{v} / \mathrm{v})$ antifoam B), and clarified by centrifugation at 100,000 $\mathrm{g}$ for 3

478 min. Total protein concentrations were measured using BCA assay and $100 \mu \mathrm{g}$ of lysate from

479 each sample was used in the immunoprecipitation. $8 \mu \mathrm{g}$ of $\alpha-\mathrm{FLAG}$ (F3165, Sigma Aldrich) was

480 conjugated to $10 \mathrm{mg}$ epoxy-coated M-270 magnetic beads (ThermoFisher Scientific) (Cristea and

481 Chait, 2011). The $\alpha-F L A G$ conjugated beads were washed and re-suspended in IP lysis buffer,

482 and $3 \mathrm{mg}$ bead aliquots were added to the clarified lysates. Lysates were incubated with magnetic

483 beads overnight at $4{ }^{\circ} \mathrm{C}$. After three washes with IP lysis buffer, bound proteins were eluted with

$48450 \mu \mathrm{l} 1 \times$ LDS sample buffer and resolved on 4-20\% Bis-Tris NuPAGE gel. Additionally, 10\% of

485 the eluate volume was resolved on a 3-8\% Tris-Tricine gel to confirm expression and enrichment

486 of the immunoprecipitated $3 \mathrm{~A}-\mathrm{FLAG}^{*}$ bait. Proteins were transferred to PVDF membranes and 
487 immunoblotted with a-GBF1 (ab86071; abcam, at 1:1000 dilution) and HRP conjugated a-FLAG

488 (A8592; Millipore Sigma 1:2000 dilution). The experiment was performed in triplicate.

\section{Cell viability assay}

490 Cell viability assays were performed in 96-well plates using the CellTiterBlue reagent (Promega).

491 Working concentrations of GCA were prepared by diluting a $10 \mathrm{mM}$ DMSO-solubilized stock in

492 complete media. Equimolar solutions lacking the drug were prepared by diluting neat DMSO.

493 Cells were incubated in $100 \mu \mathrm{l}$ of GCA or DMSO working solutions for $48 \mathrm{~h}$ before $20 \mu \mathrm{l}$ of the

494 CellTiterBlue reagent was added, and fluorescence was measured 4 h-post addition using a

495 Synergy HTX Multi-mode plate reader (BioTek). The metabolically active cells convert the blue

496 redox reagent into its fluorescent product with the number of live cells directly proportional to the

497 intensity of the fluorescent product. Fluorescence measurements from the drug-treated samples

498 are normalized using the signal from matched DMSO-treated samples.

499 For the viability assay validating GBF1-SL candidates, 20,000 cells of each gene KD cell

500 line (ARF1 KD, HSP90AB KD, CSK KD, PRKAA1 KD, ARF4 KD, MSMO1 KD) were seeded per

501 well in $200 \mu \mathrm{l}$ media. The next day, the media was replaced with $100 \mu \mathrm{l}$ of GCA or DMSO at 1.5

$502 \mu \mathrm{g} / \mathrm{ml}$ and $4 \mu \mathrm{g} / \mathrm{ml}$, incubated for $48 \mathrm{~h}$, and cell viability was measured as described above.

503 Normalized cell viabilities of the KD cells were compared to that of the MSMO1 KD controls.

$504 \quad$ For generating GCA dose response curves we used an automated high throughput liquid

505 handling system (PipetteMax, Gilson) for co-plating cells and the drug. Stock solutions of GCA or

506 DMSO were prepared in complete media at a concentration of $200 \mu \mathrm{M}$, and serially diluted in cell-

507 containing media of $A R F 1 \mathrm{KD}$ and MSMO1 KD $(400,000$ cells $/ \mathrm{ml})$ to obtain $0-100 \mu \mathrm{M}$ of

508 GCA/DMSO with 20,000 cells/ well, plated in triplicate. Cell viabilities were measured $48 \mathrm{~h}$ post-

509 incubation as described above. GCA dose response curves were plotted with GraphPad Prism 8.

510 For the proof-of-concept SL viability experiments, 60,000 cells of $A R F 1$ KD and MSMO1

511 KD were seeded in a 6-well plate and transfected the following day with 3A-FLAG* or an empty 
512 plasmid control. After 24 h post transfection, cells were harvested, counted, and plated in 96-well

513 plate at a density of 5000 cells per well. The remaining cells were processed for flow cytometry

514 analysis to measure transfection efficiencies. Cell viabilities were measured $48 \mathrm{~h}$ post-transfection

515 using CellTiterBlue reagent, as described above. Absolute cell viabilities of ARF1 KD and MSMO1

516 KD cells were compared using a multiple T-test, i.e., the two-stage step-up method of Benjamini,

517 Krieser and Yekutieli (Benjamini et al., 2006), in GraphPad Prism 8. The experiment was

518 performed in triplicate.

\section{Online supplemental material}

520 Table S1 contains supporting data reporting the GCA CRISPR screen results for the 19,029

521 Refseq genes. For each gene, we report the RANKS (Robust Analytics and Normalization for

522 Knockout Screens) score, associated p-values, the FDR, the number sgRNA considered for the

523 analysis, and the gene-level $\log _{2}$ fold changes. Fig. 51 contains the results from a GCA dose-

524 response assay used to determine the concentration of GCA in the CRISPR screen reported in

525 Fig 2. Fig. S2 contains supporting immunoblots that show the efficiency of the shRNA-mediated

526 protein depletion for the ARF1, MSMO1, ARF4, PRKAA1, CSK, and HSP9O KD cell lines.

\section{Acknowledgments}

528 This work was supported by National Institutes of Health grants R01 GM112108 and P41

529 GM109824 to J.D. Aitchison, and R21 Al151344 to A. Kaushansky and foundation grant FDN-

530167277 from the Canadian Institutes of Health Research to M. Tyers/

531 J.D. Aitchison, A.T. Navare, F.D. Mast, M. Tyers, T. Bertomeu, P. Olivier, and M. Neal are

532 inventors on a provisional patent disclosing synthetic lethal approaches described in this 533 manuscript.

534 Author Contributions: J.D. Aitchison, F.D. Mast, and A.T. Navare wrote the original draft of the 535 manuscript. F.D Mast, A.T. Navare, J.P. Olivier, L.N. Carpp, T. Bertomeu, and J. Coulombe- 
bioRxiv preprint doi: https://doi.org/10.1101/2020 10.12 336487 this version posted November 6, 2020. The copyright holder for this preprint

(which was not certified by peer review) is the author/funder, who has granted bioRxiv a license to display the preprint in perpetuity. It is made available under aCC-BY-NC-ND 4.0 International license.

536 Huntington designed and performed the experiments and interpreted results. M. Neal analyzed

537 data and interpreted results. J.D. Aitchison, A. Kaushansky, and M. Tyers designed and oversaw

538 experiments and revised manuscript drafts. All authors read and commented on the manuscript. 


\section{REFERENCES}

Basler, C.F., N.J. Krogan, D.W. Leung, and G.K. Amarasinghe. 2019. Virus and host interactions critical for filoviral RNA synthesis as therapeutic targets. Antiviral Res. 162:90-100. doi:10.1016/j.antiviral.2018.12.006.

Beijersbergen, R.L., L.F.A. Wessels, and R. Bernards. 2017. Synthetic lethality in cancer therapeutics. Annu. Rev. Cancer Biol. doi:10.1146/annurev-cancerbio-042016-073434.

Beller, M., C. Sztalryd, N. Southall, M. Bell, H. Jäckle, D.S. Auld, and B. Oliver. 2008. COPI complex is a regulator of lipid homeostasis. PLoS Biol. 6:2530-2549. doi:10.1371/journal.pbio.0060292.

Belov, G.A., N. Altan-Bonnet, G. Kovtunovych, C.L. Jackson, J. Lippincott-Schwartz, and E. Ehrenfeld. 2007. Hijacking Components of the Cellular Secretory Pathway for Replication of Poliovirus RNA. J. Virol. 81:558-567. doi:10.1128/jvi.01820-06.

Belov, G.A., Q. Feng, K. Nikovics, C.L. Jackson, and E. Ehrenfeld. 2008a. A critical role of a cellular membrane traffic protein in poliovirus RNA replication. PLoS Pathog. doi:10.1371/journal.ppat.1000216.

Belov, G.A., Q. Feng, K. Nikovics, C.L. Jackson, and E. Ehrenfeld. 2008b. A critical role of a cellular membrane traffic protein in poliovirus RNA replication. PLoS Pathog. 4. doi:10.1371/journal.ppat.1000216.

Belov, G.A., M.H. Fogg, and E. Ehrenfeld. 2005. Poliovirus Proteins Induce Membrane Association of GTPase ADP-Ribosylation Factor. J. Virol. 79:7207-7216. doi:10.1128/jvi.79.11.7207-7216.2005.

Benjamini, Y., A.M. Krieger, and D. Yekutieli. 2006. Adaptive linear step-up procedures that control the false discovery rate. Biometrika. doi:10.1093/biomet/93.3.491.

Bertomeu, T., J. Coulombe-Huntington, A. Chatr-aryamontri, K.G. Bourdages, E. Coyaud, B. Raught, Y. Xia, and M. Tyers. 2018. A High-Resolution Genome-Wide CRISPR/Cas9 Viability Screen Reveals Structural Features and Contextual Diversity of the Human CellEssential Proteome. Mol. Cell. Biol. 38. doi:10.1128/mcb.00302-17.

Boone, C., H. Bussey, and B.J. Andrews. 2007. Exploring genetic interactions and networks with yeast. Nat. Rev. Genet. doi:10.1038/nrg2085.

Brass, A.L., D.M. Dykxhoorn, Y. Benita, N. Yan, A. Engelman, R.J. Xavier, J. Lieberman, and S.J. Elledge. 2008. Identification of host proteins required for HIV infection through a functional genomic screen. Science (80-. ). 319:921-926. doi:10.1126/science.1152725.

Brown, M.B., and A.B. Forsythe. 1974. Robust tests for the equality of variances. J. Am. Stat. Assoc. doi:10.1080/01621459.1974.10482955.

Bryant, H.E., N. Schultz, H.D. Thomas, K.M. Parker, D. Flower, E. Lopez, S. Kyle, M. Meuth, N.J. Curtin, and T. Helleday. 2005. Specific killing of BRCA2-deficient tumours with inhibitors of poly(ADP-ribose) polymerase. Nature. doi:10.1038/nature03443.

Carpp, L.N., R.S. Rogers, R.L. Moritz, and J.D. Aitchison. 2014. Quantitative proteomic analysis of host-virus interactions reveals a role for golgi brefeldin a resistance factor 1 (GBF1) in dengue infection. Mol. Cell. Proteomics. 13:2836-2854. doi:10.1074/mcp.M114.038984.

Carrasco-Hernandez, R., R. Jácome, Y.L. Vidal, and S.P. de León. 2017. Are RNA viruses candidate agents for the next global pandemic? A review. ILAR J. 58:343-358. doi:10.1093/ilar/ilx026.

Chantalat, S., R. Courbeyrette, F. Senic-Matuglia, C.L. Jackson, B. Goud, and A. Peyroche. 2003. 
A novel Golgi membrane protein is a partner of the ARF exchange factors Gea1p and Gea2p. Mol. Biol. Cell. doi:10.1091/mbc.E02-10-0693.

de Chassey, B., L. Meyniel-Schicklin, J. Vonderscher, P. André, and V. Lotteau. 2014. Virus-host interactomics: New insights and opportunities for antiviral drug discovery. Genome Med. 6. doi:10.1186/s13073-014-0115-1.

Citterio, C., A. Vichi, G. Pacheco-Rodriguez, A.M. Aponte, J. Moss, and M. Vaughan. 2008. Unfolded protein response and cell death after depletion of brefeldin A-inhibited guanine nucleotide-exchange protein GBF. Proc. Natl. Acad. Sci. U. S. A. 105:2877-2882. doi:10.1073/pnas.0712224105.

Claude, A., B.-P. Zhao, C.E. Kuziemsky, S. Dahan, S.J. Berger, J.-P. Yan, A.D. Armold, E.M. Sullivan, and P. Melançon. 1999. GBF1: A Novel Golgi-associated BFA-resistant Guanine Nucleotide Exchange Factor That Displays Specificity for ADP-ribosylation Factor 5. 146. 71-84 pp.

Cotto, K.C., A.H. Wagner, Y.Y. Feng, S. Kiwala, A.C. Coffman, G. Spies, A. Wollam, N.C. Spies, O.L. Griffith, and M. Griffith. 2018. DGIdb 3.0: A redesign and expansion of the drug-gene interaction database. Nucleic Acids Res. doi:10.1093/nar/gkx1143.

Cristea, I.M., and B.T. Chait. 2011. Conjugation of magnetic beads for immunopurification of protein complexes. Cold Spring Harb. Protoc. doi:10.1101/pdb.prot5610.

Dixon, S.J., B.J. Andrews, and C. Boone. 2009. Exploring the conservation of synthetic lethal genetic interaction networks. Commun. Integr. Biol. doi:10.4161/cib.7501.

Dobzhansky, T. 1946. Genetics of natural populations; recombination and variability in populations of Drosophila pseudoobscura. Genetics.

Donaldson, J.G., and C.L. Jackson. 2011. ARF family G proteins and their regulators: Roles in membrane transport, development and disease. Nat. Rev. Mol. Cell Biol. 12:362-375. doi:10.1038/nrm3117.

Drees, B.L., V. Thorsson, G.W. Carter, A.W. Rives, M.Z. Raymond, I. Avila-Campillo, P. Shannon, and T. Galitski. 2005. Derivation of genetic interaction networks from quantitative phenotype data. Genome Biol. doi:10.1186/gb-2005-6-4-r38.

Ellong, E.N., K.G. Soni, Q.-T. Bui, R. Sougrat, M.-P. Golinelli-Cohen, and C.L. Jackson. 2011. Interaction between the Triglyceride Lipase ATGL and the Arf1 Activator GBF1. PLoS One. 6:e21889. doi:10.1371/journal.pone.0021889.

Enard, D., and D.A. Petrov. 2020. Ancient RNA virus epidemics through the lens of recent adaptation in human genomes. Philos. Trans. R. Soc. Lond. B. Biol. Sci. doi:10.1098/rstb.2019.0575.

Farhat, R., M. Ankavay, N. Lebsir, J. Gouttenoire, C.L. Jackson, C. Wychowski, D. Moradpour, J. Dubuisson, Y. Rouillé, and L. Cocquerel. 2018. Identification of GBF1 as a cellular factor required for hepatitis E virus RNA replication. Cell. Microbiol. 20. doi:10.1111/cmi.12804.

Farmer, H., H. McCabe, C.J. Lord, A.H.J. Tutt, D.A. Johnson, T.B. Richardson, M. Santarosa, K.J. Dillon, I. Hickson, C. Knights, N.M.B. Martin, S.P. Jackson, G.C.M. Smith, and A. Ashworth. 2005. Targeting the DNA repair defect in BRCA mutant cells as a therapeutic strategy. Nature. 434:917-921. doi:10.1038/nature03445.

García-Mata, R., and E. Sztul. 2003. The membrane-tethering protein p115 interacts with GBF1, an ARF guanine-nucleotide-exchange factor. EMBO Rep. 4:320-325. doi:10.1038/sj.embor.embor762. 
Gaur, P., A. Munjal, and S.K. Lal. 2011. Influenza virus and cell signaling pathways. Med. Sci. Monit. 17. doi:10.12659/MSM.881801.

Gordon, D.E., J. Hiatt, M. Bouhaddou, V. V. Rezelj, S. Ulferts, H. Braberg, A.S. Jureka, K.

631

632

633

634

635

636

637 Obernier, J.Z. Guo, J. Batra, R.M. Kaake, A.R. Weckstein, T.W. Owens, M. Gupta, S. Pourmal, E.W. Titus, M. Cakir, M. Soucheray, M. McGregor, Z. Cakir, G. Jang, M.J. O'Meara, T.A. Tummino, Z. Zhang, H. Foussard, A. Rojc, Y. Zhou, D. Kuchenov, R. Hüttenhain, J. Xu, M. Eckhardt, D.L. Swaney, J.M. Fabius, M. Ummadi, B. Tutuncuoglu, U. Rathore, M. Modak, P. Haas, K.M. Haas, Z.Z.C. Naing, E.H. Pulido, Y. Shi, I. Barrio-Hernandez, D. Memon, E. Petsalaki, A. Dunham, M.C. Marrero, D. Burke, C. Koh, T. Vallet, J.A. Silvas, C.M. Azumaya, C. Billesbølle, A.F. Brilot, M.G. Campbell, A. Diallo, M.S. Dickinson, D. Diwanji, N. Herrera, N. Hoppe, H.T. Kratochvil, Y. Liu, G.E. Merz, M. Moritz, H.C. Nguyen, C. Nowotny, C. Puchades, A.N. Rizo, U. Schulze-Gahmen, A.M. Smith, M. Sun, I.D. Young, J. Zhao, D. Asarnow, J. Biel, A. Bowen, J.R. Braxton, J. Chen, C.M. Chio, U.S. Chio, I. Deshpande, L. Doan, B. Faust, S. Flores, M. Jin, K. Kim, V.L. Lam, F. Li, J. Li, Y.-L. Li, Y. Li, X. Liu, M. Lo, K.E. Lopez, A.A. Melo, F.R. Moss, P. Nguyen, J. Paulino, et al. 2020a. Comparative hostcoronavirus protein interaction networks reveal pan-viral disease mechanisms. Science (80.). doi:10.1126/science.abe9403.

Gordon, D.E., G.M. Jang, M. Bouhaddou, J. Xu, K. Obernier, K.M. White, M.J. O'Meara, V. V. Rezelj, J.Z. Guo, D.L. Swaney, T.A. Tummino, R. Hüttenhain, R.M. Kaake, A.L. Richards, B. Tutuncuoglu, H. Foussard, J. Batra, K. Haas, M. Modak, M. Kim, P. Haas, B.J. Polacco, H. Braberg, J.M. Fabius, M. Eckhardt, M. Soucheray, M.J. Bennett, M. Cakir, M.J. McGregor, Q. Li, B. Meyer, F. Roesch, T. Vallet, A. Mac Kain, L. Miorin, E. Moreno, Z.Z.C. Naing, Y. Zhou, S. Peng, Y. Shi, Z. Zhang, W. Shen, I.T. Kirby, J.E. Melnyk, J.S. Chorba, K. Lou, S.A. Dai, I. Barrio-Hernandez, D. Memon, C. Hernandez-Armenta, J. Lyu, C.J.P. Mathy, T. Perica, K.B. Pilla, S.J. Ganesan, D.J. Saltzberg, R. Rakesh, X. Liu, S.B. Rosenthal, L. Calviello, S. Venkataramanan, J. Liboy-Lugo, Y. Lin, X.P. Huang, Y.F. Liu, S.A. Wankowicz, M. Bohn, M. Safari, F.S. Ugur, C. Koh, N.S. Savar, Q.D. Tran, D. Shengjuler, S.J. Fletcher, M.C. O'Neal, Y. Cai, J.C.J. Chang, D.J. Broadhurst, S. Klippsten, P.P. Sharp, N.A. Wenzell, D. KuzuogluOzturk, H.Y. Wang, R. Trenker, J.M. Young, D.A. Cavero, J. Hiatt, T.L. Roth, U. Rathore, A. Subramanian, J. Noack, M. Hubert, R.M. Stroud, A.D. Frankel, O.S. Rosenberg, K.A. Verba, D.A. Agard, M. Ott, et al. 2020b. A SARS-CoV-2 protein interaction map reveals targets for drug repurposing. Nature. 583:459-468. doi:10.1038/s41586-020-2286-9.

Goueslain, L., K. Alsaleh, P. Horellou, P. Roingeard, V. Descamps, G. Duverlie, Y. Ciczora, C. Wychowski, J. Dubuisson, and Y. Rouille. 2010. Identification of GBF1 as a Cellular Factor Required for Hepatitis C Virus RNA Replication. J. Virol. 84:773-787. doi:10.1128/jvi.0119009.

Guo, Y., T.C. Walther, M. Rao, N. Stuurman, G. Goshima, K. Terayama, J.S. Wong, R.D. Vale, P. Walter, and R. V. Farese. 2008. Functional genomic screen reveals genes involved in lipid-droplet formation and utilization. Nature. 453:657-661. doi:10.1038/nature06928.

Hartman IV, J.L., B. Garvik, and L. Hartwell. 2001. Principles for the Buffering of Genetic Variation. Princ. Buffering Genet. Var. doi:10.1126/science.1056072.

Hartwell, L.H., P. Szankasi, C.J. Roberts, A.W. Murray, and S.H. Friend. 1997. Integrating genetic approaches into the discovery of anticancer drugs. Science (80- ). 278:1064-1068. doi:10.1126/science.278.5340.1064.

Heaton, S.M. 2019. Harnessing host-virus evolution in antiviral therapy and immunotherapy. Clin. Transl. Immunol. 8. doi:10.1002/cti2.1067.

Horlbeck, M.A., A. Xu, M. Wang, N.K. Bennett, C.Y. Park, D. Bogdanoff, B. Adamson, E.D. Chow, 
674

675

676

677

678

679

680

681

682

683

684

685

686

687

688

689

690

691

692

693

694

695

696

697

698

699

700

701

702

703

704

705

706

707

708

709

710

711

712

713

714

715

716

717

718

M. Kampmann, T.R. Peterson, K. Nakamura, M.A. Fischbach, J.S. Weissman, and L.A. Gilbert. 2018. Mapping the Genetic Landscape of Human Cells. Cell. doi:10.1016/j.cell.2018.06.010.

Irwin, K.K., N. Renzette, T.F. Kowalik, and J.D. Jensen. 2016. Antiviral drug resistance as an adaptive process. Virus Evol. 2:vew014. doi:10.1093/ve/vew014.

Kaczmarek, B., J.M. Verbavatz, and C.L. Jackson. 2017. GBF1 and Arf1 function in vesicular trafficking, lipid homoeostasis and organelle dynamics. Biol. Cell. doi:10.1111/boc.201700042.

Kaelin, W.G. 2005. The concept of synthetic lethality in the context of anticancer therapy. Nat. Rev. Cancer. doi:10.1038/nrc1691.

Kaufmann, S.H.E., A. Dorhoi, R.S. Hotchkiss, and R. Bartenschlager. 2018. Host-directed therapies for bacterial and viral infections. Nat. Rev. Drug Discov. 17:35-56. doi:10.1038/nrd.2017.162.

Kawamoto, K., Y. Yoshida, H. Tamaki, S. Torii, C. Shinotsuka, S. Yamashina, and K. Nakayama. 2002. GBF1, a Guanine Nucleotide Exchange Factor for ADP-Ribosylation Factors, is Localized to the cis-Golgi and Involved in Membrane Association of the COPI Coat. Traffic. 3:483-495.

Krishnan, M.N., and M.A. Garcia-Blanco. 2014. Targeting host factors to treat West Nile and dengue viral infections. Viruses. 6:683-708. doi:10.3390/v6020683.

Lanke, K.H.W., H.M. van der Schaar, G.A. Belov, Q. Feng, D. Duijsings, C.L. Jackson, E. Ehrenfeld, and F.J.M. van Kuppeveld. 2009. GBF1, a Guanine Nucleotide Exchange Factor for Arf, Is Crucial for Coxsackievirus B3 RNA Replication. J. Virol. 83:11940-11949. doi:10.1128/jvi.01244-09.

Laurent, E.M., Y. Sofianatos, A. Komarova, J.-P. Gimeno, P. Samavarchi Tehrani, D.-K. Kim, H. Abdouni, M. Duhamel, P. Cassonnet, J.J. Knapp, D. Kuang, A. Chawla, D. Sheykhkarimli, A. Rayhan, R. Li, O. Pogoutse, D.E. Hill, M.A. Calderwood, P. Falter-Braun, P. Aloy, U. Stelzl, M. Vidal, A.-C. Gingras, G.A. Pavlopoulos, S. Van Der Werf, I. Fournier, F.P. Roth, M. Salzet, C. Demeret, Y. Jacob, and E. Coyaud. 2020. Global BiolD-based SARS-CoV-2 proteins proximal interactome unveils novel ties between viral polypeptides and host factors involved in multiple COVID19-associated mechanisms. bioRxiv.

Liang, J.O., and S. Kornfeld. 1997. Comparative activity of ADP-ribosylation factor family members in the early steps of coated vesicle formation on rat liver Golgi membranes. J. Biol. Chem. 272:4141-4148. doi:10.1074/jbc.272.7.4141.

Litton, J.K., H.S. Rugo, J. Ettl, S.A. Hurvitz, A. Gonçalves, K.H. Lee, L. Fehrenbacher, R. Yerushalmi, L.A. Mina, M. Martin, H. Roché, Y.H. Im, R.G.W. Quek, D. Markova, I.C. Tudor, A.L. Hannah, W. Eiermann, and J.L. Blum. 2018. Talazoparib in patients with advanced breast cancer and a germline BRCA mutation. N. Engl. J. Med. doi:10.1056/NEJMoa1802905.

Lum, K.K., and I.M. Cristea. 2016. Proteomic approaches to uncovering virus-host protein interactions during the progression of viral infection. Expert Rev. Proteomics. 13:325-340. doi:10.1586/14789450.2016.1147353.

Manolea, F., A. Claude, J. Chun, J. Rosas, and P. Melançon. 2008. Distinct functions for Arf guanine nucleotide exchange factors at the Golgi complex: GBF1 and BIGs are required for assembly and maintenance of the Golgi stack and trans-Golgi network, respectively. Mol. Biol. Cell. 19:523-535. doi:10.1091/mbc.E07-04-0394. 
Martínez, J., F. Arnoldi, E. Schraner, C. Eichwald, D. Silva-Ayala, E. Lee, E. Sztul, Ó. Burrone, S. López, and C. Arias. 2019. The guanine nucleotide exchange factor GBF1 participates in rotavirus replication. bioRxiv. 619924. doi:10.1101/619924.

Mast, F.D., T. Herricks, K.M. Strehler, L.R. Miller, R.A. Saleem, R.A. Rachubinski, and J.D. Aitchison. 2018. ESC RT-III is required for scissioning new peroxisomes from the endoplasmic reticulum. J. Cell Biol. 217:2087-2102. doi:10.1083/jcb.201706044.

Mast, F.D., A.T. Navare, A.M. van der Sloot, J. Coulombe-Huntington, M.P. Rout, N.S. Baliga, A. Kaushansky, B.T. Chait, A. Aderem, C.M. Rice, A. Sali, M. Tyers, and J.D. Aitchison. 2020. Crippling life support for SARS-CoV-2 and other viruses through synthetic lethality. J. Cell Biol. 219. doi:10.1083/jcb.202006159.

McManus, K.J., I.J. Barrett, Y. Nouhi, and P. Hieter. 2009. Specific synthetic lethal killing of RAD54B-deficient human colorectal cancer cells by FEN1 silencing. Proc. Natl. Acad. Sci. U. S. A. doi:10.1073/pnas.0813414106.

Mendes-Pereira, A.M., S.A. Martin, R. Brough, A. McCarthy, J.R. Taylor, J.S. Kim, T. Waldman, C.J. Lord, and A. Ashworth. 2009. Synthetic lethal targeting of PTEN mutant cells with PARP inhibitors. EMBO Mol. Med. doi:10.1002/emmm.200900041.

Meyniel-Schicklin, L., B. De Chassey, P. André, and V. Lotteau. 2012. Viruses and interactomes in translation. Mol. Cell. Proteomics. doi:10.1074/mcp.M111.014738.

Nakai, W., Y. Kondo, A. Saitoh, T. Naito, K. Nakayama, and H.W. Shin. 2013. ARF1 and ARF4 regulate recycling endosomal morphology and retrograde transport from endosomes to the Golgi apparatus. Mol. Biol. Cell. doi:10.1091/mbc.E13-04-0197.

Navratil, V., B. De chassey, L. Meyniel, S. Delmotte, C. Gautier, P. André, V. Lotteau, and C. Rabourdin-Combe. 2009. VirHostNet: A knowledge base for the management and the analysis of proteome-wide virus-host interaction networks. Nucleic Acids Res. doi:10.1093/nar/gkn794.

Nijman, S.M.B. 2011a. Synthetic lethality: General principles, utility and detection using genetic screens in human cells. FEBS Lett. 585:1-6. doi:10.1016/j.febslet.2010.11.024.

Nijman, S.M.B. 2011b. Synthetic lethality: General principles, utility and detection using genetic screens in human cells. FEBS Lett. 585:1-6. doi:10.1016/j.febslet.2010.11.024.

Okada, M. 2012. Regulation of the Src family kinases by Csk. Int. J. Biol. Sci. 8:1385-1397. doi:10.7150/ijbs.5141.

Pennings, P.S. 2013. HIV drug resistance: Problems and perspectives. Infect. Dis. Rep. 5:21-25. doi:10.4081/idr.2013.s1.e5.

Pfefferle, S., J. Schöpf, M. Kögl, C.C. Friedel, M.A. Müller, J. Carbajo-Lozoya, T. Stellberger, E. von Dall'Armi, P. Herzog, S. Kallies, D. Niemeyer, V. Ditt, T. Kuri, R. Züst, K. Pumpor, R. Hilgenfeld, F. Schwarz, R. Zimmer, I. Steffen, F. Weber, V. Thiel, G. Herrler, H.-J. Thiel, C. Schwegmann-Weßels, S. Pöhlmann, J. Haas, C. Drosten, and A. von Brunn. 2011. The SARS-Coronavirus-Host Interactome: Identification of Cyclophilins as Target for PanCoronavirus Inhibitors. PLoS Pathog. 7:e1002331. doi:10.1371/journal.ppat.1002331.

Prussia, A., P. Thepchatri, J.P. Snyder, and R.K. Plemper. 2011. Systematic approaches towards the development of host-directed antiviral therapeutics. Int. J. Mol. Sci. doi:10.3390/ijms12064027.

Reiling, J.H., A.J. Olive, S. Sanyal, J.E. Carette, T.R. Brummelkamp, H.L. Ploegh, M.N. Starnbach, and D.M. Sabatini. 2013. A Creb3-arf4 Signalling Pathway Mediates the 
Response to Golgi Stress and Susceptibility to Pathogens. Nat. Cell Biol. doi:10.1038/ncb2865.

Richards, A.L., J.A.P. Soares-Martins, G.T. Riddell, and W.T. Jackson. 2014. Generation of unique poliovirus RNA replication organelles. MBio. 5. doi:10.1128/mBio.00833-13.

Rosenberg, R. 2015. Detecting the emergence of novel, zoonotic viruses pathogenic to humans. 72:1115-1125. doi:10.1007/s00018-014-1785-y.

Rowlands, M., C. McAndrew, C. Prodromou, L. Pearl, A. Kalusa, K. Jones, P. Workman, and W. Aherne. 2010. Detection of the ATPase activity of the molecular chaperones Hsp90 and Hsp72 using the transcreener ${ }^{\top \mathrm{T}}$ ADP assay kit. J. Biomol. Screen. 15:279-286. doi:10.1177/1087057109360253.

Saeed, M., S. Kapell, N.T. Hertz, X. Wu, K. Bell, A.W. Ashbrook, M.T. Mark, H.A. Zebroski, M.L. Neal, M. Flodström-Tullberg, M.R. MacDonald, J.D. Aitchison, H. Molina, and C.M. Rice. 2020. Defining the proteolytic landscape during enterovirus infection. PLOS Pathog. 16:e1008927. doi:10.1371/journal.ppat.1008927.

Sáenz, J.B., W.J. Sun, J.W. Chang, J. Li, B. Bursulaya, N.S. Gray, and D.B. Haslam. 2009. Golgicide A reveals essential roles for GBF1 in Golgi assembly and function. Nat. Chem. Biol. 5:157-165. doi:10.1038/nchembio.144.

Sanjuán, R., M.R. Nebot, N. Chirico, L.M. Mansky, and R. Belshaw. 2010. Viral Mutation Rates. J. Virol. 84:9733-9748. doi:10.1128/jvi.00694-10.

Sanli, T., G.R. Steinberg, G. Singh, and T. Tsakiridis. 2014. AMP-activated protein kinase (AMPK) beyond metabolism: A novel genomic stress sensor participating in the DNA damage response pathway. Cancer Biol. Ther. 15:156-169. doi:10.4161/cbt.26726.

Shannon, P., A. Markiel, O. Ozier, N.S. Baliga, J.T. Wang, D. Ramage, N. Amin, B. Schwikowski, and T. Ideker. 2003. Cytoscape: A software Environment for integrated models of biomolecular interaction networks. Genome Res. doi:10.1101/gr.1239303.

Soni, K.G., G.A. Mardones, R. Sougrat, E. Smirnova, C.L. Jackson, and J.S. Bonifacino. 2009. Coatomer-dependent protein delivery to lipid droplets. J. Cell Sci. 122:1834-1841. doi:10.1242/jcs.045849.

Stukalov, A., V. Girault, V. Grass, V. Bergant, O. Karayel, C. Urban, D.A. Haas, Y. Huang, L. Oubraham, A. Wang, S.M. Hamad, A. Piras, M. Tanzer, F.M. Hansen, T. Enghleitner, M. Reinecke, T.M. Lavacca, R. Ehmann, R. Wölfel, J. Jores, B. Kuster, U. Protzer, R. Rad, J. Ziebuhr, V. Thiel, P. Scaturro, M. Mann, and A. Pichlmair. 2020. Multi-level proteomics reveals host-perturbation strategies of SARS-CoV-2 and SARS-CoV. bioRxiv. 2020.06.17.156455. doi:10.1101/2020.06.17.156455.

Surma, M.A., C. Klose, D. Peng, M. Shales, C. Mrejen, A. Stefanko, H. Braberg, D.E. Gordon, D. Vorkel, C.S. Ejsing, R. Farese, K. Simons, N.J. Krogan, and R. Ernst. 2013. A lipid E-MAP identifies Ubx2 as a critical regulator of lipid saturation and lipid bilayer stress. Mol. Cell. doi:10.1016/j.molcel.2013.06.014.

Szklarczyk, D., A.L. Gable, D. Lyon, A. Junge, S. Wyder, J. Huerta-Cepas, M. Simonovic, N.T. Doncheva, J.H. Morris, P. Bork, L.J. Jensen, and C. Von Mering. 2019. STRING v11: Protein-protein association networks with increased coverage, supporting functional discovery in genome-wide experimental datasets. Nucleic Acids Res. doi:10.1093/nar/gky1131.

Teterina, N.L., Y. Pinto, J.D. Weaver, K.S. Jensen, and E. Ehrenfeld. 2011. Analysis of Poliovirus Protein 3A Interactions with Viral and Cellular Proteins in Infected Cells. J. Virol. 
doi:10.1128/jvi.02398-10.

Thaker, S.K., J. Ch'ng, and H.R. Christofk. 2019. Viral hijacking of cellular metabolism. BMC Biol. 17:59. doi:10.1186/s12915-019-0678-9.

Turner, N.C., C.J. Lord, E. lorns, R. Brough, S. Swift, R. Elliott, S. Rayter, A.N. Tutt, and A. Ashworth. 2008. A synthetic lethal siRNA screen identifying genes mediating sensitivity to a PARP inhibitor. EMBO J. doi:10.1038/emboj.2008.61.

Verheije, M.H., M. Raaben, M. Mari, E.G. Te Lintelo, F. Reggiori, F.J.M. Van Kuppeveld, P.J.M. Rottier, and C.A.M. De Haan. 2008. Mouse hepatitis coronavirus RNA replication depends on GBF1-mediated ARF1 activation. PLoS Pathog. 4. doi:10.1371/journal.ppat.1000088.

Vijayan, K., I. Cestari, F.D. Mast, E.K.K. Glennon, S.M. McDermott, H.S. Kain, A.M. Brokaw, J.D. Aitchison, K. Stuart, and A. Kaushansky. 2019. Plasmodium Secretion Induces Hepatocyte Lysosome Exocytosis and Promotes Parasite Entry. iScience. 21:603-611. doi:10.1016/j.isci.2019.10.054.

van der Vries, E., M. Schutten, P. Fraaij, C. Boucher, and A. Osterhaus. 2013. Influenza virus resistance to antiviral therapy. In Advances in Pharmacology. Academic Press Inc. 217-246.

Wang, T., J.J. Wei, D.M. Sabatini, and E.S. Lander. 2014. Genetic screens in human cells using the CRISPR-Cas9 system. Science (80-. ). doi:10.1126/science.1246981.

Welch, B.L. 1951. On the Comparison of Several Mean Values: An Alternative Approach. Biometrika. doi:10.2307/2332579.

Wessels, E., D. Duijsings, K.H.W. Lanke, S.H.J. van Dooren, C.L. Jackson, W.J.G. Melchers, and F.J.M. van Kuppeveld. 2006a. Effects of Picornavirus 3A Proteins on Protein Transport and GBF1-Dependent COP-I Recruitment. J. Virol. 80:11852-11860. doi:10.1128/jvi.01225-06.

Wessels, E., D. Duijsings, K.H.W. Lanke, S.H.J. van Dooren, C.L. Jackson, W.J.G. Melchers, and F.J.M. van Kuppeveld. 2006b. Effects of Picornavirus 3A Proteins on Protein Transport and GBF1-Dependent COP-I Recruitment. J. Virol. 80:11852-11860. doi:10.1128/jvi.01225-06.

Wessels, E., D. Duijsings, K.H.W. Lanke, W.J.G. Melchers, C.L. Jackson, and F.J.M. van Kuppeveld. 2007. Molecular Determinants of the Interaction between Coxsackievirus Protein $3 A$ and Guanine Nucleotide Exchange Factor GBF1. J. Virol. 81:5238-5245. doi:10.1128/jvi.02680-06.

Wessels, E., D. Duijsings, T.K. Niu, S. Neumann, V.M. Oorschot, F. de Lange, K.H.W. Lanke, J. Klumperman, A. Henke, C.L. Jackson, W.J.G. Melchers, and F.J.M. van Kuppeveld. 2006c. A Viral Protein that Blocks Arf1-Mediated COP-I Assembly by Inhibiting the Guanine Nucleotide Exchange Factor GBF1. Dev. Cell. 11:191-201. doi:10.1016/j.devcel.2006.06.005.

Wiltshire, T.D., C.A. Lovejoy, T. Wang, F. Xia, M.J. O'Connor, and D. Cortez. 2010. Sensitivity to poly(ADP-ribose) polymerase (PARP) inhibition identifies ubiquitin-specific peptidase 11 (USP11) as a regulator of DNA double-strand break repair. J. Biol. Chem. doi:10.1074/jbc.M110.104745.

Woolhouse, M., and E. Gaunt. 2007. Ecological Origins of Novel Human Pathogens. Crit. Rev. Microbiol. 33:231-242. doi:10.1080/10408410701647560.

Woolhouse, M.E.J., and L. Brierley. 2018. Epidemiological characteristics of human-infective RNA viruses. Sci. Data. 5:1-6. doi:10.1038/sdata.2018.17.

Yamayoshi, S., G. Neumann, and Y. Kawaoka. 2010. Role of the GTPase Rab1b in Ebolavirus Particle Formation. J. Virol. 84:4816-4820. doi:10.1128/jvi.00010-10. 
852 Yu, G., L.G. Wang, Y. Han, and Q.Y. He. 2012. ClusterProfiler: An R package for comparing biological themes among gene clusters. Omi. A J. Integr. Biol. 16:284-287. doi:10.1089/omi.2011.0118.

Zhou, H., M. Xu, Q. Huang, A.T. Gates, X.D. Zhang, J.C. Castle, E. Stec, M. Ferrer, B. Strulovici, D.J. Hazuda, and A.S. Espeseth. 2008. Genome-Scale RNAi Screen for Host Factors Required for HIV Replication. Cell Host Microbe. 4:495-504.

859 Zotenko, E., J. Mestre, D.P. O'Leary, and T.M. Przytycka. 2008. Why do hubs in the yeast protein interaction network tend to be essential: Reexamining the connection between the network 


\section{Figure Legends}

864 Figure 1. Extending the principle of synthetic lethal interactions to a virus-induced

865 hypomorph. (A) Synthetic lethality is an extreme negative genetic interaction occurring between 866 two genes. Here, genes 'A' and 'B' are not essential, and the cell remains viable upon the loss of 867 either gene, depicted by red dotted outline of 'A' or 'B', individually. However, when these 868 deletions are combined in a single cell, as visualized in the third panel, this double loss of function 869 critically impairs the cell, resulting in its death. Such gene-gene combinations are termed synthetic

870 lethal (SL) partners. (B) The principle of synthetic lethality has been successfully exploited in the 871 development of certain cancer therapies by targeting the synthetic lethal partner of the cancer872 causing oncogene, depicted by a red ' $A$ '. In the cancerous cell, gene ' $A$ ' has been mutated, 873 depicted as ' $A$ ", leading to an enhanced dependency by the cancer cell for its synthetic lethal 874 partner 'B'. Drugs that target the otherwise nonessential gene B induce cell death when combined 875 with its SL partner, $A^{*}$. Therefore, inhibiting the function of B can selectively kill cancerous cells 876 while sparing noncancerous bystander cells. (C) Like the example in cancer (B), a viral infection 877 provides opportunities for specifically targeting infected cells by synthetic lethality. When a cell is 878 infected, host factors, depicted as the red letter ' $A$ ', are recruited by viral proteins to support viral 879 reproduction. The normal function of the host factor is thus attenuated by the presence of the 880 virus, inducing a hypomorph, red letter ' $A$ ', which sensitizes the infected cell to inhibition of its 881 synthetic lethal partner by an inhibitory drug.

882 Figure 2. A chemogenomic screen identifies synthetic lethal partners of GBF1. (A) A 883 schematic of the experimental design for chemogenomic screening with the GBF1 inhibitor 884 golgicide A (GCA). A CRISPR extended knockout (EKO) library of NALM6-Cas9 cells was treated 885 with $2 \mu \mathrm{g} / \mathrm{ml}$ doxycycline to induce individual gene knockouts via Cas9 expression. The pooled 886 library was split into individual flasks and grown over 8 days period in the presence or absence of $8874 \mu \mathrm{M}$ golgicide $\mathrm{A}$ (GCA). Following incubation, guide RNA frequencies were measured using 
888 Illumina sequencing, and $\log _{2}$ fold changes between GCA and control samples were compared.

889 (B) A plot of relative sgRNA frequencies of all genes showing genes passing a 0.05 FDR cutoff

890 in white circles. The 53 genes with negative sgRNA fold change from GCA treatment represent

891 putative synthetic lethal interactors of GBF1. The 17 genes with overrepresented sgRNAs and

892 positive sgRNA fold change represent GBF1 suppressors that may confer protection against

893 GCA. (C) Gene ontology functional enrichment analysis of synthetic lethal partners of GBF1. The

89453 putative synthetic lethal partners of GBF1 were analyzed in clusterProfiler against the entire

$895 \mathrm{KO}$ gene collection from the CRISPR library to functionally classify the SL genes. Significantly

896 enriched gene ontologies are plotted and ranked by their $-\log _{10}$, FDR-adjusted enrichment $p$ -

897 value. The number of putative synthetic lethal genes in each gene ontology is coded by the

898 heatmap and ranges from 3 (yellow) to 9 (pink). (D) A combined PPI network of the 53 synthetic

899 lethal interactors of GBF1 (green circles) and the 17 GBF1 suppressors (orange circles) was

900 obtained from the STRING database and visualized using Cytoscape. Edges between two circles

901 denote evidence-based interaction between the connecting proteins. Circles with red outlines

902 highlight known targets of viral proteins, as per the VirHostNet (v2.0) virus-host PPIs database.

903 Gene names of the proteins and their gene ontology functions are color matched.

904 Figure 3. Validation of putative synthetic lethal interactions in HeLa cells. (A) ARF1 displays

905 a robust synthetic lethal interaction with GBF1. ARF1, HSP90, CSK, PRKAA1, the control gene

906 MSMO1, and the top GBF1 suppressor gene ARF4 were silenced in HeLa cells with shRNA-

907 mediated lentivirus transductions and incubated with 1.5 or $4 \mu \mathrm{M}$ golgicide $\mathrm{A}$ (GCA) or DMSO for

90848 h. CellTiterBlue reagent was added and fluorescence measurements were collected. Live cells

909 metabolize the reagent into fluorescent products and an increase in the fluorescence signal is

910 directly proportional to the number of living cells. The percent viability at each GCA concentration

911 was calculated by dividing the fluorescence from a GCA-treated sample by its matched DMSO-

912 treated control. Changes in cell viabilities for each knockdown (KD) cell line were determined by 
913 comparing the respective percent viabilities to the MSMO1 KD control using a Brown Forsythe

914 and Welch ANOVA multiple comparison test (Brown and Forsythe, 1974; Welch, 1951), with

915 statistically significant differences are indicated as: * if $p$-value $<0.01$; ${ }^{* *}$ if $p$-value $<0.001$; ${ }^{* * *}$ if

$916 p$-value $<0.0001$. Error bars represent the SEM from three biological replicates. (B) ARF1 KD

917 cells show enhanced sensitivity in a GCA dose-response curve. A GCA or DMSO working

918 solution $(200 \mu \mathrm{M})$ was serially diluted and co-plated with 20,000 cells per well of ARF1 KD and

919 MSMO1 KD cells in a 96-well plate, with final GCA or DMSO concentrations ranging from 0 - 100

$920 \mu \mathrm{M}$. After $48 \mathrm{~h}$, cell viability was measured with CellTiterBlue and the normalized fluorescence,

921 relative to the DMSO-treated samples, was calculated using the smallest and largest mean values

922 to define $0 \%$ and $100 \%$, respectively. A dose reponse curve of the normalized fluorescence was

923 plotted against the $\log _{10}$ GCA concentration and $\mathrm{IC}_{50}$ values were calculated using the a four

924 parameter logistic regression model in Graphpad. Error bars represent the SEM from three

925 biological replicates.

926 Figure 4. Poliovirus nonstructural protein 3A induces a vi-hypomorph of GBF1. (A)

927 Poliovirus 3A physically interacts with GBF1. HeLa cells were transfected with FLAG* tagged

928 poliovirus $3 \mathrm{~A}$ or an empty control plasmid for $24 \mathrm{~h}$. Equal amounts of lysates were prepared, and

929 immunoaffinity enriched for bound protein complexes to 3A-FLAG* protein. Affinity captured

930 proteins were eluted and resolved on SDS-PAGE along with $1 \%$ of the total input lysate and the

931 final wash. Resolved proteins were transferred to a nitrocellulose membrane and immunoblotted

932 using anti-GBF1 (top panel) and anti-FLAG (bottom panel) antibodies. (B) Poliovirus 3A

933 redistributes GBF1 away from its perinuclear localization. HeLa cells transfected with FLAG*

934 tagged poliovirus 3A or an empty control plasmid were fixed, stained with fluorescently labeled

935 antibodies against FLAG and GBF1, and imaged by wide-field fluorescence microscopy. Bar 5

$936 \mu \mathrm{M}$. (C-D) Images of GBF1 were analyzed and the distances of each GBF1 puncta to the nearest

937 nucleus was determined and plotted across the entire distance range (C) and between $20 \mu \mathrm{M}$ to 
$93840 \mu \mathrm{M}(\mathrm{D})$ for 42 control cells and 13 cells transfected with 3A-FLAG*. The corresponding box

939 plots show statistically significant differences in GBF1 distribution between the two samples with

$940 \quad * * *$ representing a $p$-value $<0.0001$.

941 Figure 5. Synthetic lethal killing of a vi-hypomorph of GBF1. (A) Expression of poliovirus 3A-

942 FLAG* in ARF1 and MSMO1. Each gene was stably silenced in HeLa cells and transfected with

943 FLAG*-tagged poliovirus 3A. The expression levels of 3A-FLAG $48 \mathrm{~h}$ post transfection were

944 measured by flow cytometry. (B) Poliovirus 3A induces cell death in ARF1 KD cells. Cell viabilities

945 of ARF1 KD and MSMO1 KD cells transfected with $3 \mathrm{~A}-\mathrm{FLAG}{ }^{*}$ or an empty plasmid control were

946 measured using the fluorescence readout of CellTiterBlue. A change in fluorescence is directly

947 proportional to the number of living cells, and a decrease in the absolute fluorescence indicates

948 reduced cell viability. Percent viabilities of ARF1 KD and MSMO1 KD cells were calculated by

949 dividing the absolute fluorescence values of 3A-transfected samples by the matched empty-

950 transfected samples. Multiple t-test was used to compare percent viability between the 3A-treated

951 ARF1 KD and MSMO1 KD cells with ${ }^{* * * * *}$ representing P-value $<0.000001$. Error bars represent

952 the SEM from six biological replicates. 


\section{A synthetic lethality}

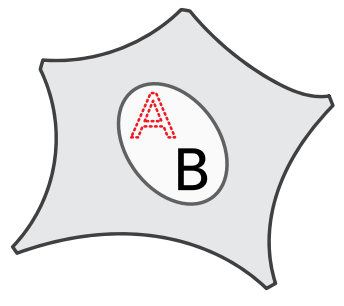

viable

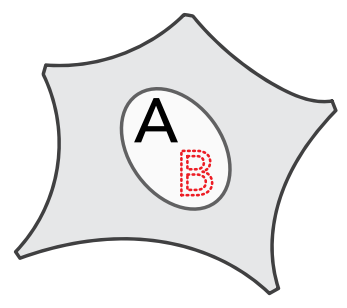

viable

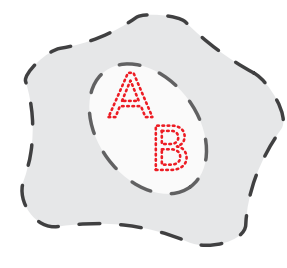

dead

B synthetic lethal targeting of cancer

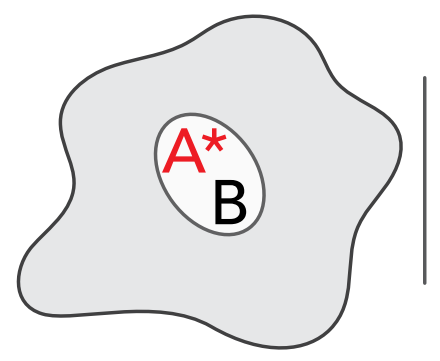

viable

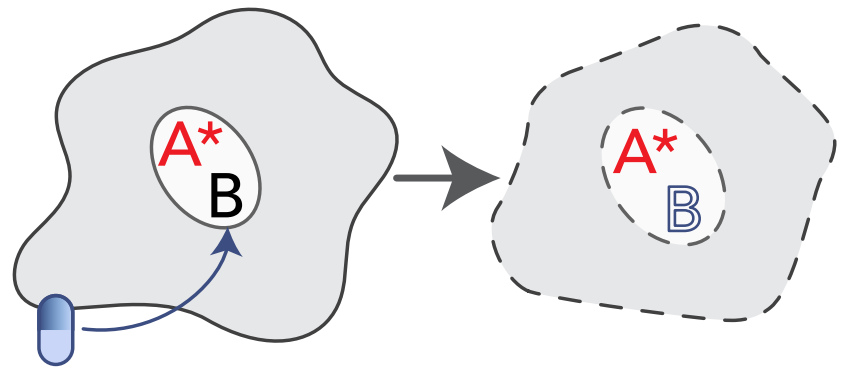

drugging SL

dead partner of $A^{*}$

C synthetic lethal targeting of a viral-induced hypomorph

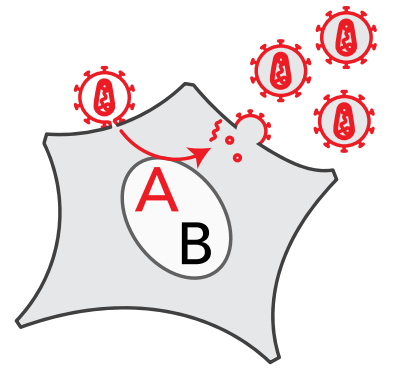

viable

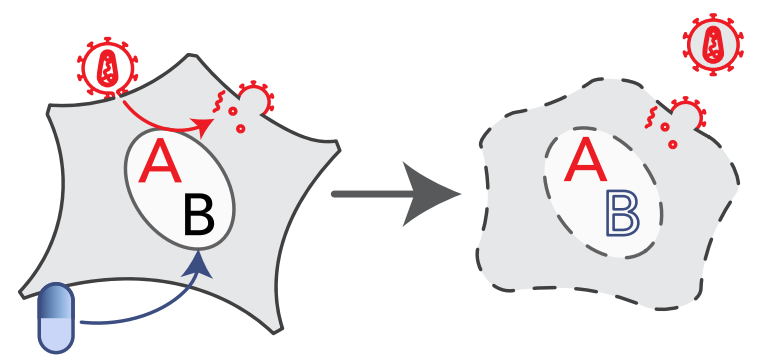

drugging SL

dead 


\section{A}

NALM6-Cas9 cells

$$
\begin{aligned}
& \text { (0) (O) } \\
& \text { (ㅇ) (0) } \\
& \text { ○ல๐லం }
\end{aligned}
$$

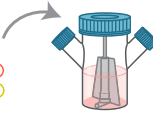
pooled EKO library $(278,754$ sgRNAs):
19,084 refseq genes $(192,202$ sgRNAs) 20,852 alt.-spliced exons $(58,615$ sgRNAs $)$

3,872 predicted genes $(33,982 \mathrm{sgRNAs})$ non-targeting (2,043 sgRNAs)

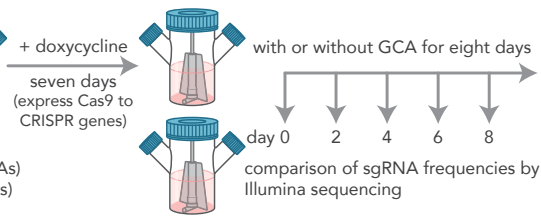

C

response to unfolded protein

response to topologically incorrect protein

regulation of response to endoplasmic reticulum stress

negative regulation of response to endoplasmic reticulum stress

response to endoplasmic reticulum stress

negative regulation of TOR signaling

endoplasmic reticulum unfolded protein response

macroautophagy

cellular response to unfolded protein

cellular response to topologically incorrect protein

regulation of TOR signaling

regulation of macroautophagy

TOR signaling

negative regulation of catabolic process

protein folding

negative regulation of proteolysis involved in cellular protein catabolic process

retrograde protein transport, ER to cytosol

endoplasmic reticulum to cytosol transport

regulation of ERAD pathway

negative regulation of cellular catabolic process

negative regulation of cellular protein catabolic process

\section{autophagy}

process utilizing autophagic mechanism

negative regulation of intracellular signal transduction

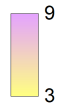

$\mathrm{N}$ proteins with

GO annotation

found in screen
1 2
3

- $\log _{10}$ (FDR-adjusted enrichment p-value)
B

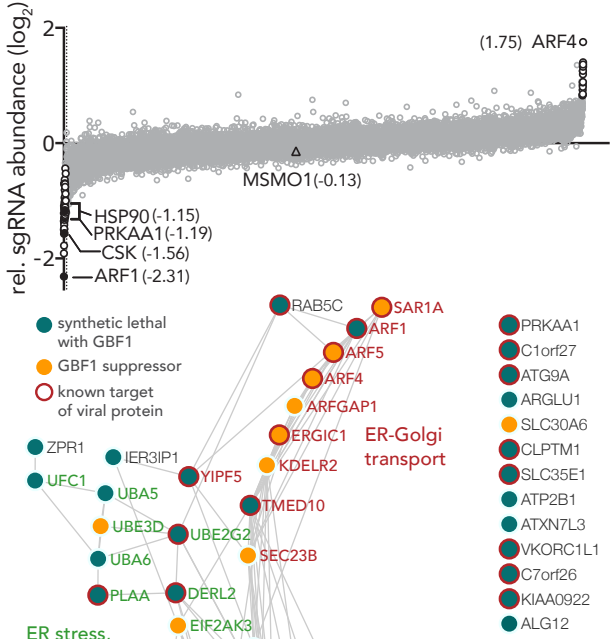

ER stress,

unfolded protein

response,

ER-associated

degradation

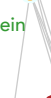

SEC 31A

ALG12

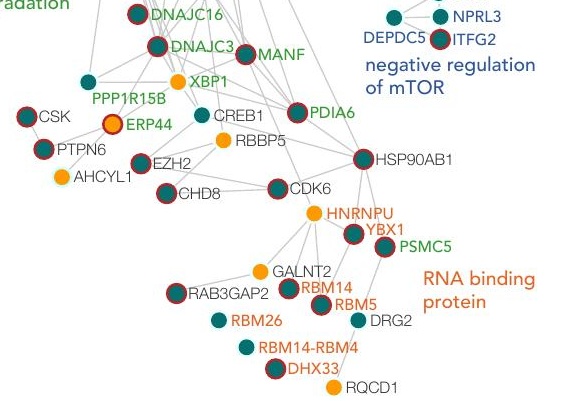

\section{Navare et al Figure 2}


A

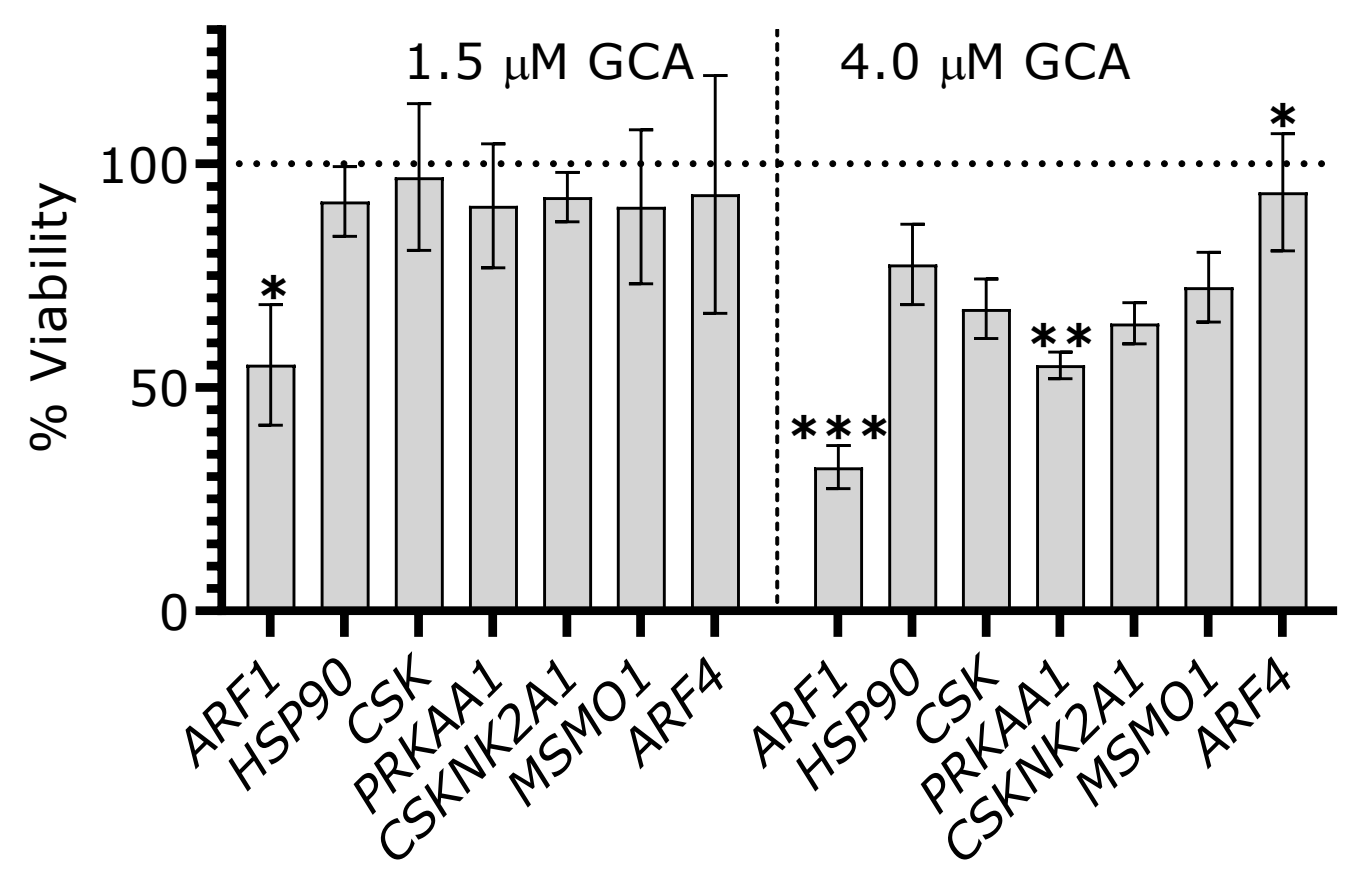

B

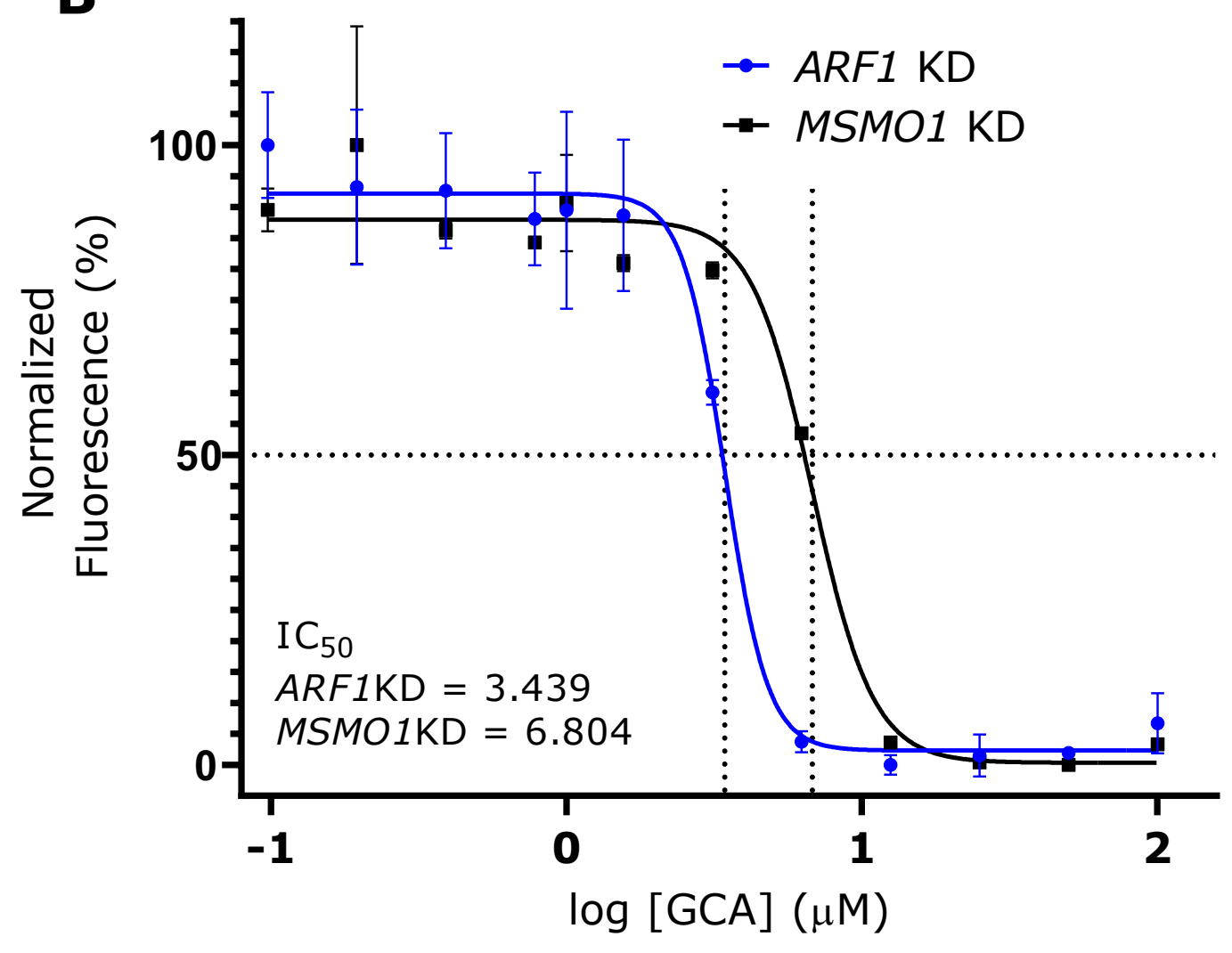




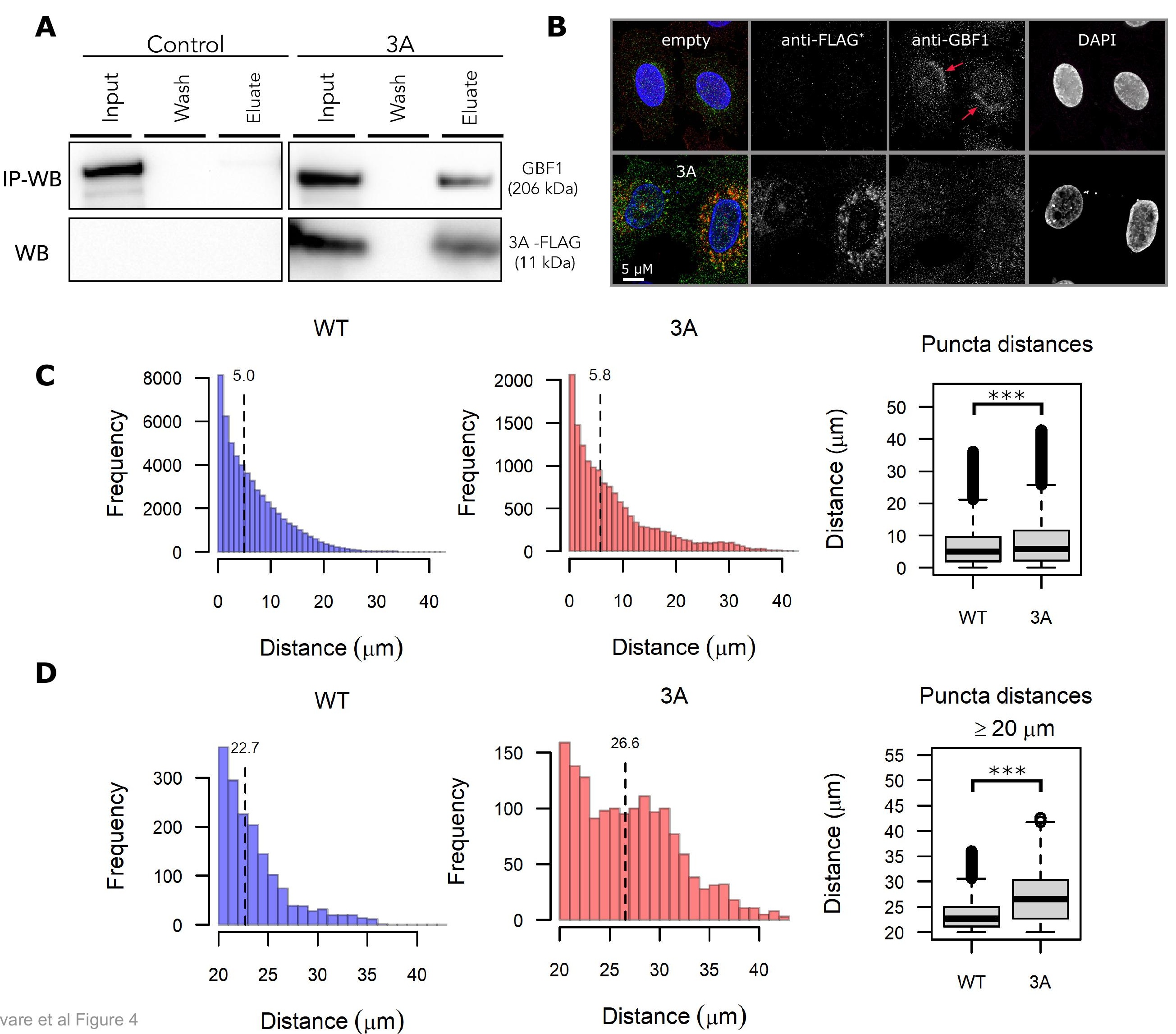


A

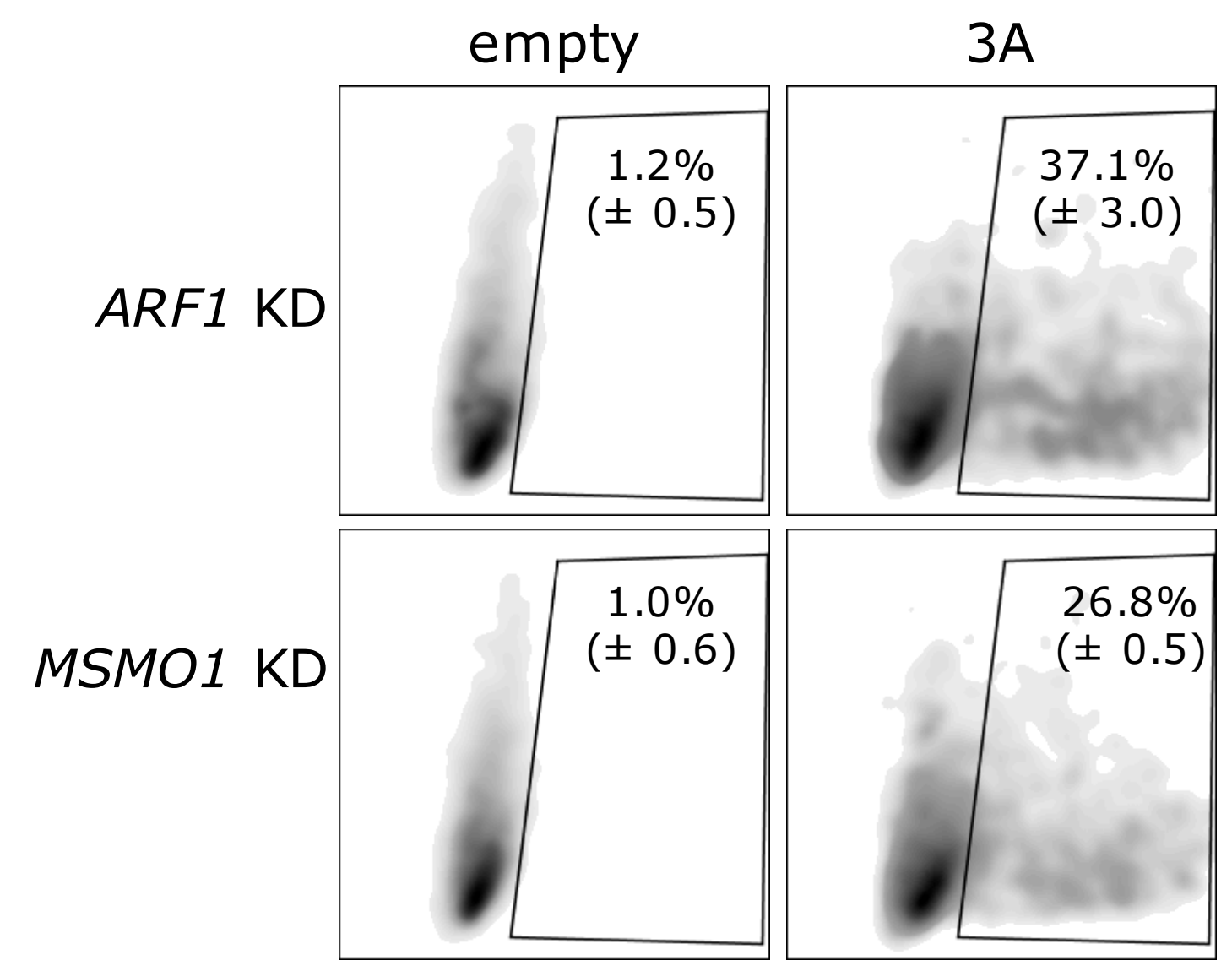

B

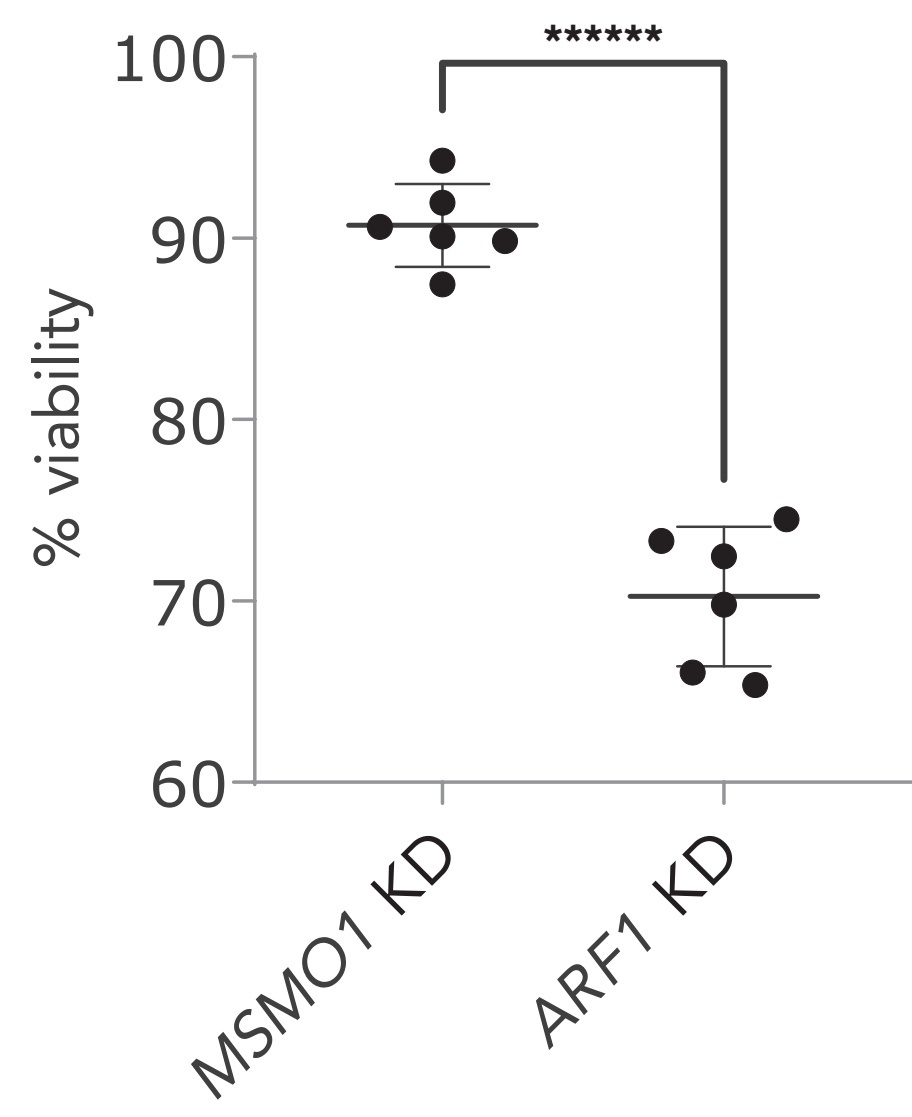

